\title{
ESTUDIOS
}

\section{Músicas inmigrantes latinoamericanas en Santiago de Chile: el caso de la escena musical peruana}

\author{
Latin American Inmigrant Musics in Santiago de Chile: \\ The Peruvian Music Scene
}

\author{
por \\ Marisol Facuse M. \\ Departamento de Sociología, Facultad de Ciencias Sociales, \\ Universidad de Chile, Chile \\ marisolfacuse@uchile.cl
}

Rodrigo Torres A.

Departamento de Música, Facultad de Artes, Universidad de Chile, Chile

rtorres@uchile.cl

La investigación que aquí presentamos se ha propuesto estudiar las músicas inmigrantes latinoamericanas en Santiago de Chile en el período 1990-2015, con el fin de comprender su relación con las identidades, las sociabilidades y los imaginarios de las comunidades que las hacen vivir. Mediante observaciones de campo y entrevistas comprensivas hemos analizado diversas experiencias en que se reúne música e inmigración, profundizando en el caso de la escena musical peruana. Para ello comenzamos por una contextualización histórica de esta práctica musical en su país de origen y luego abordamos su reconfiguración en la ciudad de Santiago, considerando la creación de nuevas redes y de lugares de música, hasta esos momentos inéditos, constituidos a partir de la experiencia migratoria. Asimismo, hemos dado especial énfasis a las trayectorias de los artistas que han protagonizado estos procesos de migración musical y a los imaginarios por ellos transmitidos, los que a nuestro modo de ver pueden contribuir al surgimiento de nuevos mestizajes culturales.

Palabras clave: Santiago de Chile, músicas inmigrantes latinoamericanas, escena musical peruana, mestizajes culturales.

The aim of the research leading to this article is the understanding of how Latin American immigrant musics in Santiago de Chile during 1990-2015 relate to identity, sociability and imaginaries of the communities that bring them to life. Through field observations and comprehensive interviews, several interrelating experiences of music and immigration are analyzed, focusing on the music scene of the Peruvian community in Santiago. Firstly the historical background of the musical practices in question are considered in terms of their country of origin. Next their changes in Santiago are discussed, in terms of how networks and new music spaces come about as a result of the migratory experience. A special emphasis is given to the study of the individual lives of the artists that act as protagonists of these music migration processes, as well as of the imaginaries mobilized therein, which we consider can lead to the emergence of new cultural mestizajes.

Keywords: Santiago de Chile, Latin American music migrations, Peruvian music scene, cultural mestizajes. 


\section{MÚSICAS INMIGRANTES LATINOAMERICANAS EN SANTIAGO: UNA PRÁCTICA EMERGENTE ${ }^{1}$}

El propósito de la investigación que aquí presentamos ha sido comprender el vínculo entre música e inmigración a partir de la experiencia de los músicos latinoamericanos residentes en Chile y de la constitución de nuevas escenas musicales (Bennett 2004) que hemos reconocido como la de las músicas inmigrantes.

Una primera aproximación al fenómeno de la migración musical ${ }^{2}$ en el contexto chileno nos lleva a visualizarla como una práctica emergente, resultado del aceleramiento de los flujos migratorios que se han producido en las últimas décadas. En efecto, así como dan cuenta numerosos estudios, desde 1990, el número de la población de inmigrantes en Chile se ha incrementado sostenidamente, superando hoy la cifra de 477.000 personas $^{3}$. La estimación del Ministerio de Desarrollo Social, fundada en la Encuesta de Caracterización Socioeconómica Nacional -Casen 2013-, nos indica que desde el 2006 al 2013 el número de inmigrantes se duplicó, pasando de ser el $1 \%$ al 2,1\% de la población total del país (Ministerio de Desarrollo Social, 2015). Por otra parte, de acuerdo con las informaciones del Departamento de Extranjería y Migración del Ministerio del Interior (2016: 23), esta inmigración proviene principalmente de países latinoamericanos, siendo la más significativa aquella proveniente de Perú $(31,7 \%)$, seguida de Argentina (16,3\%), Bolivia (8,8\%), Colombia $(6,1 \%)$, Ecuador $(4,7 \%)$, Brasil $(3,0 \%)$ y Venezuela $(1,9 \%)$.

Esta nueva realidad demográfica presente mayoritariamente en el Gran Santiago, trae consigo el surgimiento de nuevas prácticas culturales -musicales, dancísticas, gastronómicas, rituales, festivas-, así como particulares modos de habitar el espacio urbano ${ }^{4}$, que nos permiten caracterizar la ciudad como un espacio cada vez más heterogéneo. Se trata de una condición reconocida y valorizada por algunos de los municipios de la Región Metropolitana ${ }^{5}$, los que comienzan a proclamarse como comunas multiculturales.

En este contexto, actores institucionales organizan y apoyan regularmente actividades con las comunidades inmigrantes en las que la música y la gastronomía juegan un rol fundamental como un medio en donde estas comunidades se ponen en escena, sirviendo a la vez como punto de partida para los intercambios culturales 6 .

1 Este artículo ha sido realizado en el marco del proyecto Fondecyt regular N 110928 "El mundo de las músicas inmigrantes latinoamericanas en Chile: identidades, sociabilidades y mestizajes culturales", en que los autores del artículo son los investigadores responsables. El equipo de investigación está formado por Ignacia Villagra, Malén Cayupi, Constanza Lobos, Pablo Albornoz y Daniela Forné con el apoyo de Ana Cubides, Francisca Cornejo y Jorge Leiva. A todos dirigimos nuestros agradecimientos. Más información acerca del proyecto y sus resultados en el sitioweb www.musicasmigrantes.cl

2 Al respecto ver Frances y Jáquez 2003; Toynbee y Dueck 2011.

3 Agencia EFE, Santiago de Chile, 19 marzo 2016.

4 Ver Imilan, Stefoni y Márquez 2015.

5 Es el caso de los municipios de Santiago, Estación Central, Recoleta, Independencia y Quilicura.

6 Algunas de estas actividades son el Día Nacional del Perú (Recoleta, Estación Central, Quinta Normal, La Reina), el Día Nacional de Colombia, el Día del Refugiado y el Día del Inmigrante 
Este nuevo panorama cultural presente en el espacio urbano nos lleva a considerar las músicas inmigrantes como un fenómeno emergente ${ }^{7}$, asumiendo este término en una doble acepción, como urgencia y como innovación. Sin subestimar las condiciones de precariedad y de violencia social que enfrenta gran parte de la población inmigrante latinoamericana en Chile (Tijoux 2007), nos interesamos aquí por valorar el potencial creativo de estos actores, y comprender cómo sus prácticas culturales pueden contribuir a la diversidad social y cultural de nuestro país.

Como releva Marta Torres, estudiar los efectos culturales de la inmigración implica considerar "los sentimientos, las emociones, la construcción de sueños, la memoria, la habilidad para vivir en dos mundos de manera paralela y frecuentemente simultánea” (Torres 2012: 305). En una perspectiva similar sostendremos que la música puede jugar un rol fundamental en la reconfiguración de identidades de los inmigrantes en su encuentro con otros y en los procesos de reconfiguración de sí, pudiendo operar como mediadora entre el pasado y el presente; entre el territorio de origen y el de destino, considerando tanto su dimensión real como imaginaria.

Por su parte, Íñigo Sánchez (2008a) en su trabajo acerca de las prácticas musicales de cubanos en Barcelona destaca el papel de la música en la construcción de los imaginarios de los sujetos diaspóricos. Para este autor la música constituye un recurso especialmente significativo para evocar lugares, movilizar emociones, organizar memorias colectivas y entregar puntos de identificación.

Es necesario advertir que la investigación que aquí presentamos, si bien busca contribuir a un análisis global acerca de las dimensiones artísticas y culturales del fenómeno migratorio, no pretende situarse como un trabajo especializado en el ámbito de la sociología de las migraciones. Más bien se plantea como una continuidad de las investigaciones desarrolladas por sus autores respecto de mundos del arte y culturas populares en América Latina (Facuse 2012 y 2011; Torres 2011 y 2008), confiriendo un particular énfasis al fenómeno musical y a su relación con la reconfiguración de identidades y mestizajes culturales.

\section{Métodos, terrenos y casos}

Pesquisar lo que hemos comprendido como la escena de las músicas inmigrantes en Chile implicó la observación directa de situaciones en las que estas músicas se presentan en diversos contextos, como restaurantes, festivales, ferias, conciertos, fiestas nacionales y religiosas, entre otros. Junto con ello hemos realizado 48 entrevistas a músicos y organizadores de estas actividades, en las que también

\footnotetext{
(Quilicura), la Fiesta de la Virgen de Copacabana, Fiesta Cultural en homenaje al Carnaval de Barranquilla (Santiago Centro), Carnaval Sin Fronteras (Independencia), la Kumbiateca (Estación Central), la Feria de la Interculturalidad y Barrio (Providencia), entre muchas otras.

7 Asumimos este concepto en relación con la discusión propuesta por el proyecto Vidas cotidianas en emergencia: territorio, habitantes, prácticas del que participa este equipo investigador. Dicho núcleo de investigación es financiado por la Iniciativa Bicentenario (IB-JGM capital semilla) de revitalización de las Humanidades, las Artes, las Ciencias Sociales y las Ciencias de la Comunicación de la Universidad de Chile.
} 
se incluyeron algunos entrevistados no inmigrantes que participaban de su ejecución ya sea como aprendices ${ }^{8}$ o como personal de apoyo en la organización y producción de tales actividades (Becker 2008). Los criterios para seleccionar la muestra de los músicos entrevistados se orientaron principalmente por la fecha de su llegada a Chile, que delimitamos a partir de la década de 1990, y por el desarrollo de una práctica musical antes y después del momento de la inmigración. Orientándonos por estos criterios tomamos contacto con músicos provenientes de Perú, Colombia, Ecuador, Bolivia, Cuba, Uruguay, Brasil, Argentina, República Dominicana, Panamá y Haití.

Al iniciar la búsqueda de eventos y de posibles entrevistados nos confrontamos con una multiplicidad de tipos de casos y de escalas de observación en los que se cruzaban música e inmigración: músicos latinoamericanos residentes en Chile, músicos chilenos interesados por aprender la música de países vecinos, actividades esporádicas organizadas por municipios, parroquias o asociaciones de inmigrantes, etc. Sin embargo, en lugar de buscar homogeneizar esta realidad múltiple comparando casos similares, decidimos integrar la heterogeneidad a nuestro dispositivo de investigación, observando las músicas inmigrantes como una realidad que se nos presentaba de manera fragmentaria y en escalas diversas. Es así que nos encontramos frente a un polimorfismo de los casos (Passeron 2011), en el que se reunieron en un mismo corpus eventos y trayectorias de naturaleza diversa, los que nos daría finalmente un panorama lo más completo y detallado posible de la actualidad de estos mundos y escenas musicales. Los criterios para seleccionar las actividades a las que concurrimos estuvieron dados únicamente por la exigencia de que en ellas se reuniera música e inmigración, y que participaran de manera más o menos activa las comunidades inmigrantes. Es así que nos encontramos con experiencias musicales con diverso grado de profesionalismo y consagración artística (Heinich 1991), regularidad e institucionalización.

A partir de este corpus de entrevistas y observaciones nos abocaremos en este artículo al análisis del caso de los músicos peruanos, con el fin de comprender con mayor profundidad el carácter translocal de una escena musical particular. Previo a la presentación del análisis del material recolectado, introduciremos algunos antecedentes históricos de las músicas criollas y afroperuanas, con el objeto de situar al lector en las controversias que fueron el trasfondo de las prácticas musicales de las que aquí daremos cuenta.

\section{LAS MÚSICAS CRIOLLAS Y AFROPERUANAS. PROCESOS, ANTECEDENTES}

Perú es un territorio conocido por su carácter pluricultural y multiétnico. Actualmente se reconocen en él tres regiones geográfico-culturales que permiten dar cuenta de dicha diversidad: la costa, la sierra y la selva.

\footnotetext{
8 La noción de aprendices es utilizada por los propios participantes de grupos de música que están en formación, en particular en el caso de las agrupaciones de música y danza peruanas.
} 
A pesar de ello, en el proceso de construcción hegemónica de la nación, forjado a lo largo del siglo pasado, la representación oficial del Perú se cristalizó privilegiando los elementos de origen colonial a partir de una síntesis reconocida como la cultura criolla. Con ello quedaron en la opacidad toda una serie de influencias culturales de raíz indígena y afro. Esta primacía dada a lo criollo como representación de la cultura nacional comenzó a ser interrogada a mediados del siglo XX mediante dos procesos simultáneos. El primero fue el masivo flujo de las migraciones internas de indígenas a la ciudad, siendo especialmente decisivo el movimiento de población proveniente desde la sierra hasta Lima a partir de la década de 1940, un movimiento conocido como la cholificación de Lima (La Cruz 2010). Un segundo momento emergió en 1950, con la visibilización en el circuito artístico de Lima de la reivindicación cultural y musical de la población peruana afrodescendiente y de su pertenencia a la diáspora africana transnacional. Ambos procesos generaron transformaciones profundas, que trajeron como consecuencia una revisión crítica del discurso del criollismo.

Si bien la música criolla sigue siendo la referencia más importante de la nación peruana ${ }^{9}$, lo es con un nuevo énfasis: el reconocimiento de los fundamentos afroperuanos de lo criollo. En este sentido, emerge con propiedad el componente afro como parte constitutiva de la configuración del Perú contemporáneo como una identidad nacional compleja. Desde esta nueva situación surgen planteamientos que permiten desnaturalizar las narrativas previamente consolidadas, proponiendo otros marcos para comprender estos fenómenos, relacionándolos con una perspectiva a la vez histórica, cultural y política.

Así, Chalena Vásquez sostiene que “todo 'lo criollo’ tiene presencia afro” y que "lo criollo adquiere en el Perú su identidad gracias a los rasgos culturales afrodescendientes" (Vásquez 2010: 20-21). Heidi Feldman propone que el "Pacífico Negro" habita un espacio igualmente ambivalente con relación al "Atlántico Negro" de Paul Gilroy (1993): "Mientras la doble conciencia del Atlántico Negro resulta de la identificación dual con el África premoderna y el Occidente moderno, el Pacífico Negro negocia relaciones ambiguas con la cultura criolla y con la cultura indígena local, así como con el mismo Atlántico Negro” (Feldman 2009: 9) ${ }^{10}$.

Estas tensiones identitarias trascienden las fronteras geográficas del país si consideramos la cantidad de peruanos que históricamente han decidido emigrar al extranjero ${ }^{11}$. La experiencia de peruanos fuera del Perú, que aquí reconoceremos

9 Mario Rey, refiriéndose a la diáspora peruana en Estados Unidos señala: "Trascendiendo fronteras nacionales, la música criolla ha sido favorecida por el público peruano, independientemente de raza o clase social” (2004: 3).

10 Aclara Heidi Feldman: "Sitúo al Pacífico Negro en el Perú y (tentativamente) en otras zonas a lo largo de la costa andina del Pacífico (por ejemplo Ecuador, Bolivia, Chile y Colombia) donde la historia de la esclavitud, así como la persistencia de la gente y de las expresiones culturales de ascendencia africana, son desconocidas para muchos extranjeros" (2009: 9).

11 "En las últimas décadas las cifras de emigrantes peruanos han mostrado un marcado crecimiento y actualmente $10 \%$ de la población peruana se encuentra residiendo fuera de sus fronteras geográficas" (Abusada y Pastor 2008: 3). 
como diáspora peruana, ha sedimentado en el curso de varias décadas un espacio transnacional, en el que han tenido lugar nuevos procesos y cruces culturales.

La pregunta por la música y más específicamente por las prácticas musicales de estas comunidades diaspóricas fuera de su país de origen, nos lleva a explorar las diversas escenas locales en las que se han involucrado estos músicos en su trashumancia, así como también las nuevas escenas que se han ido creando en el encuentro con otros referentes. Las interacciones de estos músicos con universos musicales diferentes remiten a procesos de cambios y generación de nuevas experiencias y tal es el interés principal en nuestro caso.

\section{Música afroperuana, negritud y la lucha por su reconocimiento}

La contribución de los afrodescendientes a la cultura del Perú fue ampliamente desconocida e invisibilizada hasta la mitad del siglo pasado. A partir de la década de 1950 y desde las coordenadas de las tradiciones de música y danza que permanecían en la memoria de estas comunidades, se activó un proceso de recuperación y de reinvención de las tradiciones afroperuanas a partir de un nuevo tipo de escenificación. Con ello el mundo de los afrodescendientes, tanto en sus condiciones sociales como en sus tradiciones culturales, comenzó a ser valorado e integrado a la cultura artística de su país. Este renacimiento o revival (Feldman 2009: 4-5) se configuró en el cauce de un movimiento artístico colectivo de revitalización, incluso de reinvención de ese pasado, alcanzando una consolidación institucional en la década de 197012. Así, en el curso de este proceso histórico, la práctica urbana de los "ritmos negros del Perú", como los llamara Nicomedes Santa Cruz Gamarra ${ }^{13}$, logró articularse al modo de una nueva escena artística que comenzará a circular como parte de la imagen cultural del Perú, conocida y reconocida internacionalmente.

Las tradiciones artísticas y musicales afroperuanas nutrieron de manera sustantiva los repertorios, prácticas y sonoridades de la música criolla. Como hemos visto, hasta 1950 el aporte afroperuano a la música nacional fue invisibilizado y asimilado al constructo más general de la música criolla. Posteriormente, los artistas negros generaron un movimiento artístico y político que dio lugar a una nueva representación del sujeto afroperuano a partir de un gesto colectivo de autoafirmación que, en el curso de los últimos cincuenta años, alcanzó niveles inéditos tanto en el desarrollo de sus propios modos expresivos como en el de su proyección social y cultural dentro y fuera del Perú.

Esta escena afroperuana adquiere en las décadas de 1970 y 1980 la textura de una red amplia y compleja. En ella aparecen figuras de referencia, las que además de una intensa actividad creativa y de circulación en diversos escenarios,

12 En este proceso de renacimiento de danzas y músicas afroperuanas aplica lo que el historiador Eric Hobsbawm conceptualizó como "la invención de la tradición" (ver Hobsbawm 1983: 7-21).

13 Músico, investigador, poeta y escritor (Lima, 1925-1992) que lideró el movimiento artístico de reafirmación de la cultura afrodescendiente en Perú, junto con su hermana Victoria Santa Cruz (Lima, 1922-2014). 
instalan un dispositivo de transmisión y valorización social del mundo afroperuano, recreado a partir de distintos lenguajes artísticos. La constelación de referentes promovida por los "líderes del renacimiento afroperuano" (Feldman 2009: 5) fue principalmente encarnada en las trayectorias de Nicomedes Santa Cruz, Victoria Santa Cruz ${ }^{14}$, Teresa Palomino, Susana Baca, entre otros, y en agrupaciones artísticas como Cumanana, Teatro y Danzas Negras del Perú, Conjunto Nacional del Folklore, Agrupación Perú Negro y Perú Unión Santa Cruz.

Numerosos miembros participantes de esta red de actividades de la escena afroperuana en Lima se desplazarán en viajes artísticos de distinta duración y geografía. La figura del viaje comienza a ser parte del desarrollo de estas trayectorias de músicos. A este flujo contribuirá no solo la búsqueda de nuevos horizontes de desarrollo artístico y económico, sino que también la influencia de factores sociopolíticos, como las duras condiciones de la época generadas por la llamada Guerra interna y las políticas autoritarias del gobierno de Fujimori.

Jóvenes músicos, una buena parte de ellos vinculados a la comunidad afroperuana limeña, comenzaron a migrar a fines de la década de 1980 a otras latitudes. Varios de ellos viajaron a Chile como un destino temporal, en su tránsito a países como Brasil, Alemania, España o Estados Unidos. Desde su instalación en la metrópoli santiaguina, las trayectorias de estos músicos, sea de forma paralela o bien articuladas entre sí, fueron poco a poco configurando una nueva escena de la música peruana en que la presencia sostenida de prácticas, instrumentos, lugares y repertorios musicales afroperuanos contribuyó a la instalación de una renovada representación musical del Perú en el espacio cultural de la sociedad chilena.

\section{VIAJANDO CON PERÚ: LA DIÁSPORA MUSICAL PERUANA ${ }^{15}$}

Chile es uno los cinco países, junto con Argentina, España, Estados Unidos e Italia, en el que reside la mayor cantidad de peruanos que han emigrado en los últimos 20 años $^{16}$. En la actualidad la población de peruanos en Chile es la más

14 Para una aproximación al trabajo artístico de esta autora y a su lucha reivindicativa contra el racismo, ver "Me gritaron negra" (Video, 3:15 min.), en: https://www.youtube.com/ watch?v=F5vPoqDkMF0

15 "Viajando con Perú" es el nombre de un programa radial creado y realizado por el músico limeño Mario Nunura Villanueva en la radioemisora Eclipse (107.7 FM) de la comuna de Quilicura, Región Metropolitana. El nombre artístico de este músico es Tino Alegría, el que usaremos a lo largo de este artículo.

16 Al respecto, Pablo Albornoz señala que la emigración peruana más reciente ha sido principalmente hacia estos países, y precisa la dimensión de estos flujos: "Tomando en consideración únicamente estos países, nos encontramos con un 88,6\% del total de la población peruana que ha emigrado en los últimos 22 años, dentro [de] este porcentaje Chile habría recibido un 8,8\% (OIM-Perú, 2012), equivalente a 130.589 personas, siendo los mayores destinos por lejos Estados Unidos con un $31,5 \%$, equivalente a 531.358 personas, luego pero disminuyendo bastante, le seguirían España con un $16 \%$, equivalente a 198.126 personas, Argentina con un 14,3\% equivalente a 157.514 personas, e Italia con un 10,1\% equivalente a 101.711 personas. Es importante destacar que pese a que los países desarrollados recibirían el mayor porcentaje de emigrantes peruanos, migrar hacia otros países vecinos se alza como una opción importante, pues, los países sudamericanos concentrarían un $30,3 \%$ de la 
numerosa del total de la población extranjera residente y es, también, la de presencia cultural y musical más amplia, heterogénea y que ha generado la mayor zona de contacto intercultural con el país de acogida, lo que desafía las imágenes previamente consolidadas del Perú, su gente y su(s) cultura(s) ${ }^{17}$.

El reciente fenómeno migratorio Sur-Sur ha significado la emergencia -a contracorriente de la lógica migratoria Sur-Norte- de nuevas dinámicas y componentes musicales, agenciados por esta nueva y creciente población latinoamericana migrante, de la que los peruanos conforman un colectivo central.

Para dar cuenta de este agenciamiento hemos adoptado el concepto de diáspora, como una categoría analítica adecuada para explorar la experiencia de los migrantes en estos tiempos de globalización, y su impacto tanto en la sociedad receptora como en la de origen. Esta perspectiva es la que propone y trabaja Íñigo Sánchez en los siguientes términos:

"A grandes rasgos, entiendo el concepto de 'diáspora' como una categoría abierta que permite poner en relación distintas experiencias subjetivas de desplazamiento en base a un denominador común. Este denominador común se construye, principalmente, a partir de los vínculos que los sujetos diaspóricos establecen con su lugar de origen. [...] Pero además, el concepto de diáspora permite releer al desplazado como un sujeto con una capacidad de transformación del lugar elegido como destino, como otras categorías no habían permitido antes" (Sánchez 2008b: 34-35) ${ }^{18}$.

Se sabe y lo reiteramos: la música y el baile son sistemas expresivos interconectados que en procesos migratorios o diaspóricos de cruces culturales, operan como un dispositivo de alta eficacia en la reconfiguración de referentes de identidad y de memorias colectivas.

En el siguiente apartado examinaremos más de cerca los relatos de vida (Bertaux 1997) de algunos de estos músicos peruanos llegados a Chile hace casi tres décadas.

\subsection{Trayectorias de músicos y transmisión de la práctica musical}

La transmisión familiar aparece como un importante componente en las trayectorias narradas por los músicos peruanos. Así lo muestra la historia de Martín Zegarra,

emigración peruana (Argentina y Chile suman un 23,1\% del total de migrantes). Esta vendría siendo la nueva tendencia, que de hecho, indica cambios en la estructura regular de la migración sur-norte, en favor de la migración sur-sur" (2015: 16).

17 Según estimaciones del Departamento de Extranjería y Migración realizadas el 2009 para el 2010, se encontrarían en el país 352.344 personas extranjeras, equivalente a 2,08\% de la población total del país en ese año (ver Albornoz 2015: 10), siendo la población de peruanos inmigrantes significativamente la más numerosa. Hacia el 2010 se estiman en 130.859 habitantes, correspondiente a $0,77 \%$ de la población en territorio chileno (Albornoz 2015: 11). Albornoz elabora una traza que cuantifica el flujo de población peruana inmigrante en el país: de 7.649 en 1992 a 130.859 habitantes en 2010, lo que representa un crecimiento de 1.608,8\% (2015: 14). Por otra parte, "del total de emigrantes peruanos que arriban a nuestro país, el 77,9\% de ellos se encontraría en la Región Metropolitana (OIM-Perú, 2012) y 12,1\% se encontraría en la Región de Tarapacá” (2015: 16).

18 Para profundizar en el concepto de diáspora ver además, Cámara 2008 y Fernández 2008. 
percusionista y bailarín quien descubre los ritmos y la sonoridad de la música criolla y afroperuana a muy temprana edad. El prematuro encuentro a los cinco años con su tío Eusebio Sirio, "Pititi"19, reconocido como uno de los más insignes intérpretes del cajón peruano y quien frecuentaba la casa materna de Zegarra, puede ser interpretado como un punto de inflexión o peripeteia (Bruner 2013), a partir del cual se organiza su devenir de músico. Se trata en consecuencia de un aprendizaje musical por impregnación (Charles-Dominique y Aubert 2009), que caracteriza los modos de transmisión de las músicas de tradición oral en diversas partes del mundo. Este tipo de aprendizaje se caracteriza por una iniciación muy temprana a la escucha y a la práctica musical en un ambiente familiar y festivo. A diferencia del aprendizaje formal de un instrumento o de un género musical, se trata de un acercamiento a la experiencia musical en el que los afectos y las emociones así como la presencia de la música en la vida cotidiana (DeNora 2004) tendrán primacía por sobre la sistematicidad y la rigurosidad que predomina en los espacios institucionales ${ }^{20}$. Con ello nos confrontamos a un tipo particular de socialización musical, que se hace presente en la mayoría de las otras trayectorias de músicos aquí pesquisadas, caracterizada por una práctica musical que no está separada del resto de la vida social.

Asimismo, Martín inscribe su carrera de artista (Becker 2009) en filiación con el movimiento cultural y artístico afroperuano de 1960, del que hemos dado cuenta anteriormente. Algunos de sus protagonistas fueron sus maestros y a la vez los agentes que posibilitaron su ingreso a los circuitos musicales de la música criolla y afroperuana desde muy temprana edad. En este excelso grupo de músicos la figura de "Pititi", legendario miembro de la agrupación Perú Negro, constituye un referente fundamental:

"Desde que conocí y escuché por primera vez a 'Pititi' [...] fue como el principio de todo lo que es Martín Zegarra ahora, en este momento. Martín Zegarra es músico percusionista gracias a que un día conoció a Eusebio Sirio 'Pititi', cajonero de Chabuca Granda" (Martín Zegarra).

A los siete años su familia se traslada a Santa Cruz de Miraflores en Lima, donde el encuentro con otro músico que habitaba el barrio produce un nuevo giro en su trayectoria. Se trata de Augusto Polo Campos, quien lo invitó a participar en los circuitos de música criolla, en el que comenzó a trabajar con consagrados artistas de este género, como Chabuca Granda y Eva Ayllón.

19 Eusebio Bernardo Sirio Castillo. Lima, 1951-2012. Músico percusionista, bailarín y profesor de cajón.

20 A este respecto es de interés considerar la diferencia que establecen Bourdieu (1998) y Passeron (2011) entre la enseñanza en el ámbito familiar y la que ocurre en la institución escolar. La primera con una marcada presencia de los afectos, adquirida desde la más temprana edad, en contraste con la segunda, caracterizada por la rigidez y la obligatoriedad. En el caso analizado podemos agregar en el aprendizaje musical institucional una primacía de la técnica en el modo de aprendizaje, a diferencia de las músicas tradicionales o populares en que la música se da en espacios de convivencia y de encuentro con otros. 
Es de interés destacar que durante sus primeros años de músico y aprendiz Martín se desempeñó como bailarín de festejo en los grupos en los que participaba. A pesar de su motivación por interpretar instrumentos, en primera instancia había sido convocado como bailarín. Sin embargo, a la primera oportunidad que se le presentó comenzó a tocar el cajón y otros instrumentos, como él mismo lo narra:

"De repente, en un momento de descuido en que ellos [los músicos] estaban por ahí descansando yo me senté en el cajón y me puse a tocar; entonces me escucharon y dijeron "no bailas más, ahora te sientas a tocar"; entonces empecé a tocar el cajón, el bongó, las tumbadoras, la campana, y ya no me pararon más y de ahí quedé como músico" (Martín Zegarra).

En la carrera artística de Martín el oficio de bailarín continúa desarrollándose de manera paralela al de músico, con lo que va acumulando un saber-hacer que lo va transformando en un "músico completo", como se autodefinirá más adelante. Este aspecto nos permite retomar el argumento mencionado anteriormente acerca de la particularidad de las músicas populares o tradicionales en las que baile, canto e interpretación de instrumentos forman parte de una totalidad como expresión de una concepción integral del artista.

En estos primeros años de aprendizaje musical el viaje adquiere un lugar fundamental, ya que a los jóvenes más talentosos se les invitaba a las giras nacionales e internacionales. El viaje significa en la trayectoria de Martín una forma de reconocimiento y un camino hacia la consagración artística en el mundo de las músicas afroperuanas.

"Pero siempre a mí me gustaba aprender; entonces aprendí a bailar también o sea a bailar, a zapatear, a tocar todos los instrumentos. Fue así que en el grupo cuando

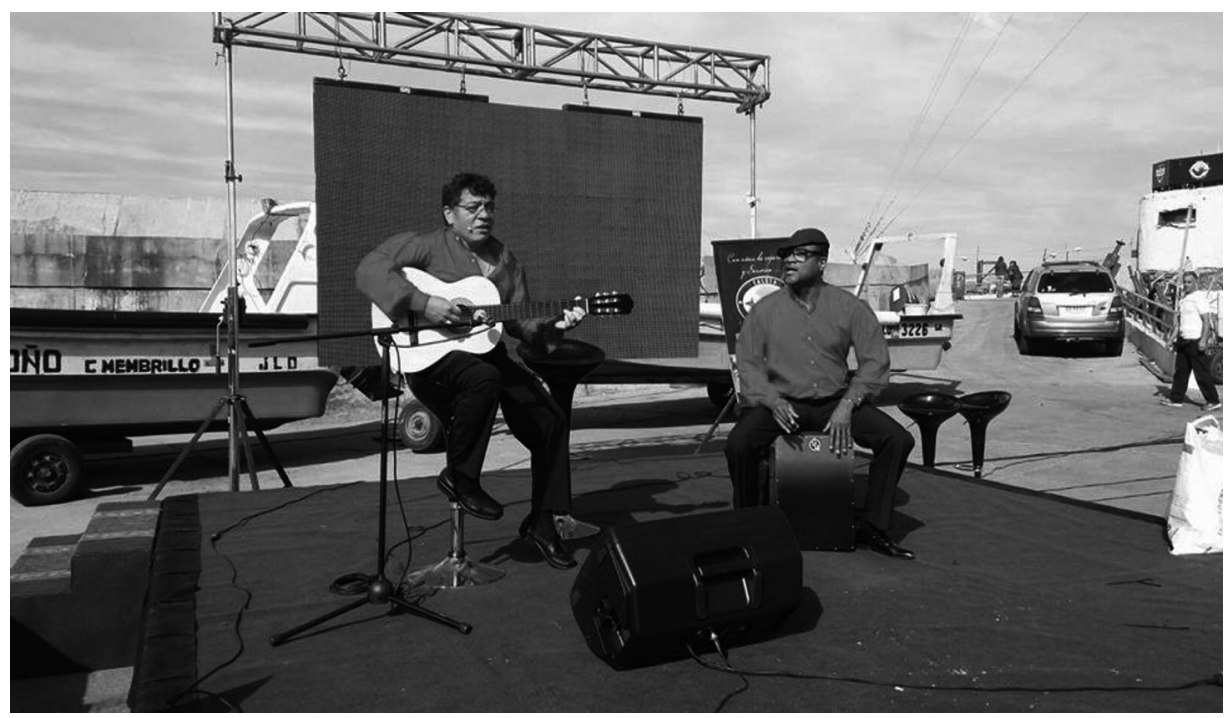

Foto 1. Martín Zegarra (cajón) y Tino Alegría (guitarra), Caleta El Membrillo, Valparaíso, 2016. 
empezamos a viajar llamaban a los mejores. Si éramos 80 viajábamos 20 o 25 y yo no me perdí ningún viaje, tuve esa suerte [...]” (Martín Zegarra).

Es en esta condición que visita Chile por primera vez a mediados de los 70, como músico profesional de la agrupación Perú Unión Santa Cruz y luego con la agrupación Perú Negro. Una década más tarde, en 1989, regresa a tocar a Chile con el grupo Fiesta Negra, viaje en el que decidirá radicarse en nuestro país.

El caso de Martín ilustra de manera clara un tipo de trayectoria. Se trata de un músico profesional reconocido en la escena de la música criolla y afroperuana en su país, la que, según vimos, en los 70 comienza a tener una gran circulación y reconocimiento internacional. Todos estos elementos constituyen en la actualidad el sustrato a partir de cual este músico se autorrepresenta y a la vez se define como representante de la cultura de su país.

Un tipo de trayectoria distinta la encontramos en otro músico peruano de la misma generación quien llegó a nuestro país también a inicios de los 90 . Se trata de Tino Alegría, de madre afroperuana y padre de origen japonés, quien igualmente cultiva la música criolla ampliándose poco a poco hacia nuevos géneros de la música popular latinoamericana, como bolero y mariachi.

Originario de una familia de músicos del popular barrio de La Victoria de Lima, en el caso de Tino se aprecia de manera más nítida aquello que hemos reconocido como el aprendizaje por impregnación. Al igual que para Martín, su primer acercamiento a la música está marcado por las relaciones afectivas y festivas y existe el reconocimiento en un cierto linaje familiar con músicos y artistas del espectáculo.

"Mi infancia en realidad fue llena de música, toda la vida; mis tíos, mi mamá, todos cantaban; se formaban orquestas en mi casa con lo que había en esa época [...] y con latas, con baldes, con la bacinica, la mesa, en la cama -en el catre en ese tiempo-, con .palos, con cucharas, hacíamos música con mis primos porque mis tíos eran músicos profesionales, tanto que grababan discos con orquestas, la Sonora Macedo ${ }^{21}$, Nelson Ferreyra y su sonora22 [...]" (Tino Alegría).

"Entonces ahí formamos las grandes jaranas entre niños. Agarrábamos las tumbadoras, si había una agarrábamos una y así fue naciendo la música pero nunca en las cuerdas, siempre en lo que es la percusión y cantar, yo no cantaba, hacía coros no más pero ahí con mis primos... y bailábamos; entonces se formaba ese ambiente cuando nos juntábamos todos los primos, era una cosa muy fantástica, tanto que realmente uno añora esas cositas porque fue un mundo musical” (Tino Alegría).

En el relato de Tino podemos distinguir distintos momentos en su socialización musical, cada uno con su temporalidad y espacialidad debidamente delimitados. Un primer momento lo podríamos reconocer como por impregnación y a la vez

21 Sonora Macedo, agrupación dirigida por el pianista Lucho Macedo (Luis Young Agüero, Lima 1930), reconocido músico de esta música tropical en Lima y Callao.

22 En la Sonora de Nelson Ferreyra, participaron Litia Branda (cantante) y su hermano Pablo Branda "Melcochita" (cantante corista y humorista), tíos de Tino Alegría. 
embodiment ${ }^{23}$, debido a la fuerte implicación emocional y corporal de su primer encuentro con la música.

En el pasaje anteriormente citado es importante destacar la cuestión de los lugares que habitó este músico en su infancia y cómo estos lo fueron poniendo en contacto con ciertas culturas musicales específicas, pudiendo tener un cierto carácter performativo para su constitución como músico. Tino se reconoce como habitante de un lugar determinado: el barrio La Victoria, como "un victoriano", un sector que él mismo caracteriza como un barrio popular, un lugar marcado por la presencia de la música y en particular por la percusión y el canto. Como vemos, en su relato se retrata con vivacidad el ambiente de fiesta en el que se despliegan estas músicas siempre acompañadas de baile en el contexto familiar y barrial, lo que reconoce como un "mundo musical".

Un segundo momento está marcado por un aprendizaje más sistemático, consciente y solitario de la música a sus quince años, época en que se inicia como guitarrista. Poco tiempo después comienza a practicar el cajón gracias a la transmisión de su madre, lo que le permite descubrir nuevos circuitos de músicos.

Un tercer momento en la trayectoria musical de Tino es su ingreso al mundo de la música criolla en Lima a los dieciocho años. En este nuevo espacio comienza un paulatino proceso de profesionalización en el que va desarrollando competencias como animador e intérprete de diversos instrumentos (charango, bongó, cajón) y va adquiriendo sus propios instrumentos, los que arrienda a otros músicos. Esta época, recordada por él como "un momento fantástico", marca una nueva peripeteia en su biografía donde comienza a recibir dinero por su trabajo como músico, y a definirse por el que será hasta hoy su género musical principal: la música criolla. Este período duró unos diez años hasta que emprendió el viaje a Chile.

En esta tercera etapa de su trayectoria, aprende de manera más sistemática las bases del cajón peruano guiado por su madre, de origen afroperuano, quien provenía de una familia de percusionistas. Ella le enseñó en el espacio doméstico, ya que según afirma, las mujeres en esa época no tocaban cajón porque no era bien considerado socialmente. Al igual que Martín Zegarra, empezó tocando en una mesa para luego iniciarse directamente con el instrumento. Sin embargo, reconoce que si bien no se dedicó a conocerlo en profundidad, este aprendizaje le fue útil para reemplazar a otros músicos en el cajón cuando la situación lo demandaba.

Durante este período se desempeñó también como representante de otros grupos musicales y artistas del mismo medio, en el que obtuvo reconocimiento y pudo alternar con importantes figuras del mundo de la música criolla.

23 La traducción literal del concepto es encarnación y si bien ha sido contundentemente utilizado por los investigadores(as) del área de la sociología del cuerpo, tiene su tradición igualmente en otras disciplinas tales como la psicología y filosofía. Muy presente en la fenomenología mediante las propuestas teóricas de Merleau Ponty y Husserl, la noción de embodiment entiende al cuerpo como centro de la identidad indisociable de sus formas de experiencia y percepción. En consecuencia, el concepto alude a la importancia del cuerpo en los procesos de interacción, como la percepción o la adquisición de la cultura por medio de los sentidos. 
“[...] pero sí, se puede decir [que trabajé] en forma profesional [...], en la Casa Blanca acompañando a Eva Ayllón por ejemplo, ahí la acompañé cuando ella recién casi empezaba. De guitarrista estaba [Javier] Munayco, el que grabó el primer long play con ella y había mucha gente, Pedrito Otiniano... Lucho Barrios24" (Tino Alegría).

Una tercera trayectoria que presentaremos es la de Wendy Lozano, que se asemeja y a la vez se distingue marcadamente de las otras dos que evocamos en varios puntos de interés para nuestro estudio. Al igual que en los dos casos examinados, en el relato de Wendy se pueden reconocer diferentes modalidades de aprendizaje. En primer lugar, al igual que en la biografía de Martín y Tino, podemos identificar una enorme presencia de la música en su entorno familiar desde pequeña. Sin embargo a diferencia de los casos anteriores, los repertorios escuchados eran de música que reconoce como latinoamericana, por su madre -originaria de la sierra-, quien en su familia tenía un grupo de música andina. Los instrumentos escuchados eran la zampoña y el charango. Recuerda también que a su madre le gustaba cantar, una afición que ella hereda y reivindica como fundamental hasta hoy.

"Yo [canto] desde muy niña por mi familia, sobre todo por parte de mi mami. En la familia de mi mamá todos cantan, cantan música latinoamericana pero de la parte de la sierra, porque nosotros vivimos en la capital y la familia de mi mami, por parte de su mamá, es de la parte de la sierra y ellos tienen un grupo así latinoamericano donde tocan zampoña, charango, de todo. Y mis tíos me influenciaron en la música y a mi mami también le gustaba cantar" (Wendy Lozano).

Un segundo modo de aprendizaje es de tipo institucional. Ocurre en el caso analizado en el Museo de Arte de Lima, al que según cuenta acudió algunas temporadas para "modular la voz". Otro espacio de aprendizaje de este tipo es el colegio, donde entre los ocho y diez años realizó presentaciones frente a un público. Pocos años después, a los catorce, continúa su interés por el canto, sin embargo su madre le impide desarrollar una temprana carrera de cantante con el fin de que diera prioridad a sus estudios.

"Me decían que tenía la voz contralto y podía cantar temas de la Ana Gabriel, de Juan Gabriel y sobre todo que tenía que tener un poquito más de dinámica, pero gracias a Dios sobre todo en eso me ha ido bien, o sea no me ha ido mal. No lo pude explotar mucho -como le digo-, [aunque] igual me salían cosas para trabajar así de noche porque allá en Perú hay sitios muy bohemios, que prácticamente es trabajar como de amanecidas y todas esas cosas. Entonces nunca tuve la oportunidad porque mi mamá decía que no, que no le gustaba que en la noche..." (Wendy Lozano).

Es importante destacar en este análisis de trayectorias de músicos la notable relevancia del componente de género en el despliegue y profesionalización de una carrera artística. En la historia de Wendy así como en la mayoría de las trayectorias

24 Javier Munayco García (Chincha, 1943-2014), importante guitarrista y arreglista de la música criolla. Pedro Otiniano (1937-2012) y Lucho Barrios (1935-2010), ambos grandes boleristas peruanos. 
de las mujeres entrevistadas se aprecia rápidamente cómo han debido sortear varias restricciones para desarrollarse como músicas o finalmente se han visto obligadas a renunciar definitivamente a aquello que Antoine Hennion ha definido como una pasión musical (Hennion 2002) debiendo relegar la práctica al espacio doméstico.

Además de la familia, la escuela y las clases del Museo de Artes, otra institución que operó como fuente de aprendizaje y espacio de práctica musical fue la iglesia católica, en la que pudo desplegar de manera más libre su motivación por el canto, con lo que la música, aunque no es desarrollada de forma profesional, cobra gran centralidad en su vida.

De manera general, esta formación musical ligada con el ámbito religioso marcó buena parte de la relación de Wendy con la música desde pequeña. El espacio de la iglesia parece haber sido el más permanente en que pudo desarrollar su práctica musical y que cultivó desde los siete a los veinticinco años, momento en que emprende su viaje a Chile.

Otra trayectoria que analizaremos es la de Rosa Vargas Advíncula, bailarina y cantante de ritmos afroperuanos quien llegó a Chile en 1992. Por parte de su familia materna Rosa se formó en un contexto pronunciadamente imbuido de la cultura afroperuana.

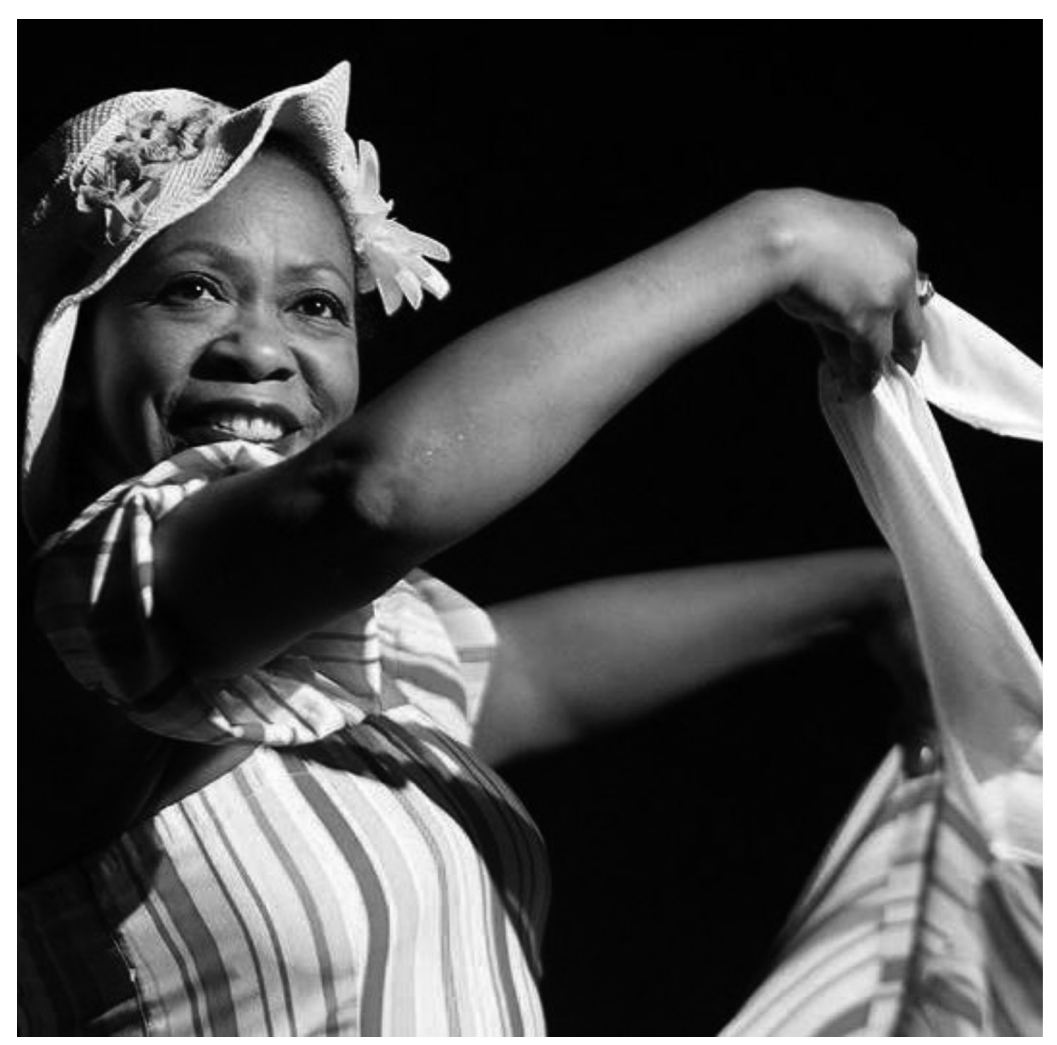

Foto 2. Rosa Vargas Advíncula, 2013. 
Su madre, originaria de Chincha, región de música afroperuana por excelencia, emigró a Lima para apoyar económicamente a su familia. A pesar de ello, Rosa mantuvo un vínculo permanente con su familia en Chincha, lugar donde pasaba largas temporadas en el verano.

En su relato, la cercanía con esta cultura musical revela con mayor nitidez su participación en el proceso de emergencia y consolidación del movimiento musical y cultural afroperuano. En sus recuerdos la presencia de la imagen materna como vectora de una transmisión es fundamental. Su madre cantaba canciones tanto del repertorio de música peruana como también boleros y tangos.

Al igual que Tino Alegría, Rosa creció en el popular barrio limeño de La Victoria. En la casa familiar la música y el baile impregnaron sus primeros años, un ambiente que nutre lo que será su ulterior proyecto artístico:

"Yo escuché la música desde que era niña porque por parte de mi mamá toda mi familia se dedicaba a la danza o eran compositores, mis tíos tocaban guitarra, cantaban, hacían décimas o payas que le llaman ustedes. Entonces yo me crie en ese ambiente, con todos mis hermanos nos criamos en ese ambiente de escuchar música siempre, de ver bailar a mis tías [...] Todos hacían música, bailaban, cantaban, mis tías, mis primas, todos, la mayoría, yo estaba niñita y desde que tenía dos años -cuando ya más o menos tú empiezas a darte cuenta de lo que es la música y esas cosas- yo vi en mi casa siempre las fiestas que duraban dos días y nos mandaban a dormir y siempre dormíamos así, la música era nuestro arrullo" (Rosa Vargas).

Este ambiente familiar en el que creció trascendía el espacio del hogar, ya que sus tíos participaron en algunos de los grupos emblemáticos del movimiento de música afroperuana en Lima entre 1950 y 1960:

"En el año 55 más o menos se formó el grupo Gente Morena de Pancho Fierro ${ }^{25}$ y en ese grupo estaban las hermanas de mi mamá, una que era cantante, otra que era bailarina, y estaba el hermano de mi mamá que tocaba la guitarra, después sus primos [...], mi tío Mario Lobatón, que es el papá de mis primos, que son los mejores músicos percusionistas en Perú, de Freddy 'Huevito’ Lobatón y Jaime 'Huevo' Lobatón, [...], uno vive ahora en Estados Unidos y el otro está en Perú26 [...]” (Rosa Vargas).

Esta pertenencia a un linaje de músicos y bailarines significó, en la trayectoria de Rosa, interiorizar las significaciones de la cultura y de la música afroperuana directamente desde quienes fueron representantes emblemáticos de tal movimiento:

"Sí pues, todos ellos formaron ese grupo, ahí estaba Victoria Santa Cruz, Nicomedes Santa Cruz, estaba Ronaldo Campos que fue el director de Perú Negro, la tía Lucila Campos, estaba Teresa Palomino, entonces toda esa gente que después, cuando se

25 En 1956 se formó la compañía Pancho Fierro, que presentó en el Teatro Municipal de Lima la primera recreación en escena de la música y los bailes afroperuanos.

26 Mario Lobatón y sus hijos Freddy y Jaime Lobatón Beltrán son miembros de una de las legendarias familias de músicos afrodescendientes del Perú. 
terminó este grupo Gente Morena de Pancho Fierro, se dispersaron y cada uno formó distintas agrupaciones" (Rosa Vargas).

Si bien Rosa no vacila en clasificar las músicas que se practicaban en este espacio como afroperuanas, explica que estos grupos también incluían repertorios de la música criolla (valses, marinera limeña). Según hemos visto anteriormente, la tradición afroperuana reivindicada en la época de los 50, si bien adquiere cierta autonomía tanto en su dimensión histórica como estética, continúa conviviendo con la música criolla y ambas representan en la actualidad lo que más se reconoce internacionalmente como música peruana.

En la época de su juventud, a los dieciséis años, Rosa participó en un casting convocado por un nuevo grupo formado por los exintegrantes de la afamada agrupación Perú Negro, y evocado también por Martín Zegarra. Se trataba del grupo Arte Negro Matalaché27, que por esta época buscaba bailarines. Rosa fue seleccionada y pasó seis meses ensayando diariamente con ellos en un lugar llamado la Concha Acústica del Campo de Marte. En su relato volvemos a encontrar el componente de género al que aludimos anteriormente, ya que, según narra, estos ensayos diarios los hacía a escondidas de sus padres.

$\mathrm{Al}$ igual que Wendy, en la trayectoria de Rosa también la Iglesia católica aparece como una institución que alberga la práctica musical mediante su participación en el coro de una parroquia, una coartada que le permitía justificar ante sus padres su asistencia a los ensayos.

En el grupo en el que participaba además de bailar cantaba los coros. Entre los repertorios que recuerda se encuentran "Taita Guaranguito" y el "Quique Iturrizaga” del género landó. Luego de estos primeros años de formación Rosa ingresa a la escuela de Victoria Santa Cruz, una referencia fundamental para su posterior trayectoria:

"Victoria Santa Cruz es hermana de Nicomedes Santa Cruz, una mujer investigadora única, única en su especie. Yo creo que esa mujer nació para hacer lo que hizo toda su vida, que fue investigar sobre nuestra música, luchar por nuestras raíces afroperuanas. Fue la mujer que dijo 'nosotros no somos negroides, nunca más digan ¡ah, qué bonito baila ese negroide!', porque ella siempre decía 'no existe el blancoide, no existe el chinoide, no existe, es negro o blanco'; decía chino o como tú le quieras llamar a las personas o a su raza o a su etnia, como le quieran llamar, pero no negroide. Ella odiaba que le dijeran negroide. Entonces con ella uno aprendía muchas cosas. Con ella aprendí otras cosas más importantes que es la fuerza, la energía, el aprender a quererse a uno mismo como persona, tener la raza negra, llevarla con orgullo, porque eso es lo que hace la Victoria y eso es lo que nos enseñó a casi todos los que en algún determinado momento pudimos pasar por su escuela" (Rosa Vargas).

27 El nombre del grupo alude a la novela Matalaché (1928) del abogado, escritor y periodista, afrodescendiente, Enrique López Albujar (1872-1966). Ambientada en la época colonial, narra los padecimientos de un hombre negro que es torturado y asesinado por su patrón en una hacienda del Perú. 
El relato de Rosa muestra de manera clara cómo en algunas trayectorias el interés por la música puede ser vehículo de procesos de identificación específicos, en este caso hacia una pertenencia étnica, sirviendo como medio de adscripción a una memoria de luchas sociales y políticas por el reconocimiento. Es importante relevar cómo se articulan en este movimiento biografías, prácticas artísticas y luchas políticas en un mismo proyecto cultural. Según hemos visto, el movimiento fundador de las músicas afroperuanas que protagonizaron sus maestros buscó sacar la producción cultural de los negros de la invisibilidad de la que era objeto, diluida en la amplia categoría de música criolla. Rosa fue testigo de este momento histórico de inflexión a partir del cual va constituyendo su identidad como artista afroperuana.

De manera general, en todas las trayectorias revisadas encontramos una gran importancia dada a la transmisión de la práctica musical por medio del linaje materno. La madre aparece en la mayoría de los casos como transmisora de una memoria sonora, por la vía del canto y la interpretación de instrumentos tradicionales como el cajón. En algunos casos estos procesos de transmisión pueden asociarse a una memoria subalterna (indígena o negra) que circula mediante la práctica musical como ocurre con el caso de las músicas afroperuanas y la música de la sierra.

Otro aspecto transversal a las biografías analizadas es el tipo de aprendizaje musical que hemos reconocido como por impregnación, experimentado en contextos de convivencia y festividad familiar. La fiesta popular es vivida como un espacio transgeneracional en el que la música juega un rol fundamental para la creación de las dinámicas colectivas. Junto con la familia el barrio aparece como un lugar esencial de socialización musical capaz de generar arraigo y sentimientos de pertenencia.

Familia y barrio vienen a constituir un dispositivo complejo de transmisión en el que se despliegan tácticas, maneras de habitar el espacio y de festejar.

En el siguiente apartado daremos una visión más exhaustiva a la constitución de una escena musical peruana en Santiago, buscando articular las trayectorias expuestas con una red mayor de interacciones y de lugares de producción musical.

\subsection{Músicos peruanos en Santiago: mundos y escenas musicales}

Desde 1990, con el retorno de la democracia, se ha ido configurando poco a poco en la ciudad de Santiago una red de músicos que podríamos reconocer como una escena musical peruana. Según hemos visto, a partir de entonces Chile se ha convertido en un lugar de destino importante para la población peruana emigrante a nivel mundial. Si bien la llegada de comunidades inmigrantes no asegura la existencia y consolidación de una escena musical particular, es un hecho que sin duda abre nuevas posibilidades para la producción y circulación de estas músicas.

Si antes de 1990 Perú activaba en la sociedad chilena un imaginario circunscrito en gran medida a las secuelas de una guerra y a la consecuente rivalidad fundada en ideales de patriotismo promovidos por la narrativa oficial, hoy es posible constatar algunas transformaciones en esta representación. Actualmente la relación con Perú se construye desde varios planos simultáneos, siendo uno muy 
importante el de la convivencia cotidiana de los individuos en el espacio barrial y laboral, especialmente en ciudades como Santiago e Iquique. Los espacios de convivencia entre chilenos y peruanos a partir de esta reciente migración han generado un inédito proceso de emergencia de nuevas relaciones interculturales en el que la zona de contacto musical ha sido decisiva y fecunda ${ }^{28}$.

La ciudad de Santiago impresionó notoriamente a los primeros músicos peruanos que emigraron a comienzos de la década de 1990. Ellos recuerdan el momento de la llegada como el encuentro con una ciudad apagada, sin lugar para la música y absorta en las transformaciones políticas en curso ${ }^{29}$. Ninguno de ellos tenía una conexión profesional con el medio musical chileno, el que entonces no representaba una plaza de interés especial para el desarrollo de sus proyectos artísticos sino que más bien era pensada como un lugar de tránsito.

"No era tan importante el espectáculo y la música para ese momento acá en Santiago. Era muy poco relevante. Obviamente por los procesos que entonces vivía Chile se veía esa cosa media gris todavía. Eso formó parte de lo que viví cuando llegué acá en 1994. [...] En Chile no había un ímpetu para hacer música para la gente ni un incentivo para formar músicos. La gente estaba en otra. Pensaba en la economía, en la democracia. Más se estilaba discutir de política que estar pensando en otras cosas. Entonces la música era poco relevante y estuvo así por un buen tiempo. Yo creo que hasta cerca del año 2000 todo fue así: tenue, todo muy tenue” (Oscar Álvarez).

En su agenciamiento con el nuevo medio, los músicos peruanos tuvieron a su haber un elemento de compatibilidad cultural muy propicio para facilitar el encuentro $^{30}$ : la memoria y experiencia previa de la sociedad chilena con la música del Perú. Esta estaba arraigada principalmente en la música criolla, con un firme anclaje en el repertorio de las décadas de 1940 a 1960. Por entonces este vínculo local con la música criolla estaba encarnado en figuras muy populares, como los cantantes Palmenia Pizarro y Lucho Barrios ${ }^{31}$, pero también estaba el antecedente de otros músicos que cultivaban regularmente el repertorio de la música criolla, como el cantante de origen peruano Eduardo "Zambo" Salas, reconocido y apreciado en el circuito de la bohemia musical de Santiago y Valparaíso desde la década de $1940^{32}$. Por otra parte, es interesante considerar que no existía un

28 Acerca de las prácticas de reconocimiento entre peruanos y chilenos a partir de la convivencia barrial y laboral, ver Forné 2015.

29 Recuerda Martín Zegarra, quien arribó a Santiago en julio de 1989: "En Perú, antes de venirme a Chile, yo vivía de la música, yo tocaba todos los días [...] los restaurantes, las peñas abrían todos los días [...] Acá, en la época que yo vine estaban recién saliendo a la democracia entonces no habían muchos locales donde se podía hacer música [...] Ahora hay más locales, incluso los restaurantes peruanos se están atreviendo a traer artistas de Perú, a las quinientas pero se atreven; ya hay un poco más de vida bohemia acá en Chile, antes no había tanto, ahora hay un poco más”.

30 Esta categoría de "zona de compatibilidad" es mencionada por Ramón Pelinski, en relación con la teoría de diseminación musical que propone Shuhei Horosawa (Pelinski 2000: 191).

31 Palmenia Pizarro González (San Felipe-Chile, 1941); Luis Barrios Rojas (Callao-Perú, 1935; Lima, 2010).

32 Eduardo 'Zambo' Salas (Lima, 1924) fue el primero en grabar en disco una versión en el estilo del vals criollo limeño del vals "La joya del Pacífico" (en sello Philips, ca. 1960) del compositor chileno 
conocimiento relevante en la escucha chilena de este renacimiento musical de la negritud peruana del que hemos dado cuenta más arriba y del repertorio que generó desde los años 60 en adelante.

"A la gente le gustaba mucho escuchar 'La flor de la canela', 'Amarraditos', que es un vals argentino pero pensaban que era peruano, 'Fina Estampa', 'Ódiame' [...] Y todavía hoy se escucha lo mismo. Es como que el oído chileno quedó ahí pegado y además con un sonido, con un referente que no es el que tenemos nosotros" (Oscar Álvarez).

A esta zona de contacto musical chileno-peruana se suma también la presencia en el imaginario chileno de la música andina, que desde los años 60 se conoció masivamente por las mediaciones realizadas por músicos chilenos que hicieron parte del movimiento de la Nueva Canción. Así lo hicieron Violeta Parra, Víctor Jara, Quilapayún, Inti Illimani e Illapu, entre otros, con versiones y reelaboraciones de repertorios, instrumentos y prácticas asociadas a "lo andino", siendo para ellos más relevante la referencia a lo andino boliviano que a la tradición musical de la sierra peruana. Excepcionalmente se dieron a conocer en el espacio de este movimiento algunas versiones de repertorios de la música afroperuana, como es el caso de Víctor Jara (“Inga”, 1970; “A la molina no voy más”, 1971) 33.

En el período comprendido en este estudio, 1990-2015, la actividad musical de la comunidad peruana en Santiago de Chile se fue decantando como un espacio abierto en el que se reconoce la coexistencia de tres sistemas musicales principales $^{34}$, con sus respectivos actores, repertorios y circuitos, y diversas articulaciones entre ellos:

a) Música de la costa: criolla y afroperuana.

b) Música andina o de la sierra.

c) Cumbia peruana, con sus variantes regionales: chicha o cumbia andina; cumbia norteña; tecnocumbia o cumbia amazónica.

Es posible identificar una relación entre distintos momentos y flujos de la emigración peruana a Chile con el tipo de música propia que cada población escucha y baila en los lugares de donde se congrega. Es decir, en la diáspora peruana en Santiago coexiste y se declina de un modo particular el mosaico musical del Perú.

Víctor Acosta. Esta versión fue la referencia inspiradora para la versión grabada en 1966 por el cantante Jorge Farías Villegas (1944-2007), “el ruiseñor de los cerros porteños”. Otros músicos peruanos que en esta época participaron activamente en el medio musical de Valparaíso fueron Carlos Reyes Orué (Lima, 1926) y Carlos Dávila Galarza (Jauja, ca. 1927). Al respecto ver Rodríguez Morales 2008.

33 Ver Acevedo et al. 1999: 349.

34 La consolidación de este repertorio diaspórico es coincidente con el que representa a la comunidad peruana en Miami, como lo señala Mario Rey: "En este repertorio se enmarcan los géneros que reflejan los valores culturales y promueven el estatus del sector dentro de la jerarquía social. Generalmente, se reconocen tres esferas principales de producción musical, estas son: 1) música andina; 2) música criolla/afroperuana; y 3) música tropical (2004: 2-3). La diferencia está en esta tercera esfera: la música tropical está asociada a la música afrocubana. El equivalente para la comunidad peruana en Santiago es la cumbia andina. 
"Yo creo que por ahí por los años 1998 y 2000 comenzó la inmigración más fuerte; llegó mucho, mucho peruano, y fue cuando empezó a sentirse fuertemente su presencia. Y aquí hay otro asunto: la emigración peruana en su mayor parte, a lo mejor el $70 \%$ u $80 \%$ de la población peruana que ha emigrado para acá no son de Lima, no son de costa y por ello no están conectados con la música criolla. La conocen sí pero no es lo más importante para ellos. En este sentido, Perú tiene otro espectro musical muy distinto" (Oscar Álvarez).

En este contexto, la ciudad de Santiago es el lugar donde se ha producido la mayor parte de experiencias del encuentro musical peruano-chileno en el ámbito de dos de los sistemas musicales mencionados: la música criolla y afroperuana y la música andina o serrana. Con el fin de no extendernos demasiado nos referiremos en este texto a la primera, dejando la segunda como tema para un futuro artículo.

\subsubsection{La Pequeña Lima}

La actividad asociada a esta escena musical generó un circuito de referencia de lo peruano en la ciudad que puede interpretarse, siguiendo los planteamientos de Martin Stokes (1994), como un proceso de construcción musical del lugar.

Un caso emblemático para ilustrar este proceso es lo que ocurrió en el entorno de la Plaza de Armas de Santiago. Durante 1990 se constituyó en el hito principal de referencia y encuentro para un importante sector de la población peruana inmigrante. En los sectores aledaños a la Plaza se instaló un sistema de comercio con servicios específicamente funcionales a esta comunidad, al punto que esta zona histórica del centro de la ciudad comenzó también a ser reconocida como "la pequeña Lima". Este fenómeno lo analiza en profundidad Ximena Póo a base de una tesis central:

"La Plaza de Armas de Santiago de Chile y su entorno se puede observar, al mismo tiempo, como un no lugar y un lugar con identidades propias donde es posible rastrear parte del mapa reciente de la migración peruana hacia Chile y es ahí donde los sujetos inmigrantes (re)construyen partes de sus relaciones, ritualidades y redes, estableciendo comunidades transnacionales -entre dos mundos- mediadas por la comunicación y el espacio urbano" (Póo 2012: 24).

Desde esta perspectiva mencionamos dos modalidades de hacer música que en su momento contribuyeron a la resignificación o peruanización de este espacio céntrico de la ciudad.

La primera es el hacer música en espacios públicos: parques, plazas, calles, transporte público, etc. Pasar el platillo -o "manguear"- fue la primera estrategia de subsistencia de los integrantes del trío Tres Sabores del Perú recién llegados a Santiago. La realizaban en distintas locaciones, como el Barrio Franklin-Matadero, Barrio Bellavista, Paseo Ahumada y Plaza de Armas.

"Nosotros tocábamos en la calle. En el Paseo Ahumada hacíamos un show me acuerdo, no teníamos una visa de trabajo, teníamos que subsistir a como dé lugar” (José Luis La Cruz). 
"Nos fuimos al Paseo Ahumada cuando estaban los Atletas de la Risa, el Flaco y el Indio, los conocimos a todos ellos, empezamos a tocar, hicimos el show, José Luis salió a bailar música negra, yo iba al cajón y ahí sí salía mejor porque hacíamos varios shows [...]" (Tino Alegría).

La segunda modalidad fue actuar en los escenarios de locales para bailar con música en vivo instalados por empresarios peruanos. Los primeros se ubicaron en el sector y constituyeron una importante plaza de sociabilidad festiva para peruanos y también chilenos. Es el caso de El Rodeo, ubicado en calle Bandera esquina de Rosas, y de La Conga Latina, ubicado en calle Catedral 1043, en la vereda opuesta de la Catedral de Santiago.

"Yo toqué en un local que se llama La Conga, muy famoso, a un costado de la Catedral [...] En ese tiempo solo existía La Conga y el peruano que venía recién decía "¿oye y cuál es el sitio que la lleva?", "La Conga"... Todos nos llegaron a conocer, éramos furor en La Conga y ahí se empezó a llenar no solamente de peruanos sino de chilenos también" (Tino Alegría).

"Fue el mismo [empresario] de El Rodeo, como ya tenía el local de baile entonces comenzó a atraer gente peruana, ahí comenzó a venir la emigración peruana [1991] [...] Comenzó a avanzar el tiempo y en el [1995] sale La Conga Latina que está ahí en Catedral [...] Ahí comenzamos a hacer nosotros fiestas para todos los emigrantes que llegaban en masa" (José Luis La Cruz).

Los fines de semana, los sábados y domingos, se hacía música criolla en vivo con cajón y guitarras. Y en la noche funcionaba como lugar para bailar con cumbia peruana.

"Y lo que se creó fueron estos locales para poder bailar pero con música que esté identificada con gente de otras zonas del Perú, que es la sierra, que es la cumbia andina. Y claro, ellos están más identificados con eso. Y por ende, al haber más inmigrantes peruanos de la sierra tenías más gente conectada con ese tipo de música. Y eso comenzó a generar todos estos locales masivos donde se escucha mucha Chicha” (Oscar Álvarez).

En esta "Pequeña Lima" -la Plaza de Armas de Santiago y su entorno-, la capacidad congregadora de la música y el baile fue puesta a prueba semana a semana durante años, creando una dimensión sonora peruana en este lugar histórico de la ciudad. Desde este primer circuito, la escena de las músicas peruanas ampliará su espectro geográfico y social en el espacio urbano, generando una red de locales, restaurantes, asociaciones, clubes sociales, talleres, academias de música y danza y también periódicos ${ }^{35}$.

35 "En Chile existen 23 clubes sociales peruanos registrados. Tres periódicos (Sol Noticias, El Bacány Contigo Perú) y un suplemento deportivo en un diario de circulación nacional (Golpé de La Cuarta), 264 restaurantes”. Carlos Pérez et al, ¿¿Qué tan peruanos somos?”, Diario La Tercera (18 de enero, 2014). En: http://www.latercera.com/noticia/tendencias/2014/01/659-561371-9-que-tan-peruanos-somos.shtml. 


\subsubsection{Sonidos y sabores del Perú}

Cuando a fines de 1989 el empresario y chef limeño Emilio Peschiera instala su restaurante El Otro Sitio en el barrio Bellavista, barrio bohemio de Santiago, se inicia un proceso que actualmente constituye el fenómeno que se ha dado en llamar como el boom de la gastronomía peruana en el país ${ }^{36}$.

En enero de 2014 se estimaba que el número de restaurantes peruanos en Chile superaba los 264, cifra que no consideraba los negocios más pequeños y populares como las cocinerías peruanas instaladas en La Vega Central, por ejemplo. Esta tupida red de restaurantes y otros sitios para comer transformó positivamente el paisaje de la inmigración peruana, constituyéndose en un factor importante de difusión de su cultura, como una zona de contacto intercultural en el que las músicas peruanas tienen presencia permanente, según una arraigada costumbre limeña en la que el rito del almuerzo se efectúa en casa y con música.

"En Perú la gente está acostumbrada a que en los restoranes siempre tiene que haber música en vivo. Si te das cuenta, los restoranes peruanos siempre tienen música, siempre. Y eso viene de una costumbre localista en Lima. La gente espera tener música a la hora del almuerzo. De hecho, antes casi todas las radios ponían música criolla al mediodía porque era la hora del almuerzo" (Oscar Álvarez).

A diferencia de Lima, donde la cultura gastronómica y la música en vivo van de la mano, en Santiago esta presencia es casi solo de música envasada, siendo muy pocos los restaurantes que ofrecen a sus clientes espectáculos con músicos peruanos. Uno de ellos es El Ají Seco Místico, lugar donde los fines de semana y desde el 2012 actúa regularmente el grupo Tres Sabores del Perú ${ }^{37}$. En su desempeño frente a una heterogénea concurrencia estos músicos han ido desarrollando un interesante tipo de performance latinoamericana plurinacional: en cada actuación organizan su repertorio desde el eje de la música criolla, pero siempre atentos a comunicarse con las sensibilidades musicales del variado público latinoamericano que concurre al local (chilenos y peruanos por cierto, pero también brasileños, argentinos, colombianos, bolivianos, etc.). La preocupación de estos músicos es la de ofrecer un repertorio y una sonoridad que satisfaga las expectativas e imaginarios musicales de los públicos presentes en cada jornada. De este modo han ampliado el espectro del repertorio que pueden entregar: "Y llegan colombianos

36 El restaurante El Otro Sitio nace en Lima en 1973, en el distrito de Barranco, frente al conocido puente de Los Suspiros. Su creador, el empresario y chef Emilio Peschiera desarrolló su proyecto gastronómico con una dimensión cultural, transformándolo en un innovador exponente de la cultura peruana en general. Entre viajes a Santiago, comienza a notar las favorables condiciones para introducir su proyecto en el mercado chileno. Su concepto "Gastronomía + cultura", más su reconocida frase "Pongámosle mantel largo a la comida peruana", fueron motivaciones fundamentales para instalar El Otro Sitio en Santiago. Para mayor información, ver: http://elotrositio.cl/el-otro-sitio-su-historia/

37 El Ají Seco Místico está situado en el centro de Santiago (calle Mac Iver 480, frente a la Basílica de la Merced) y forma parte de la cadena de restaurantes El Ají Seco, que cuenta con once locales en la Región Metropolitana y dos en Viña del Mar. 
y obligados a tocar una cumbia colombiana, hasta bachata para los portorriqueños y dominicanos”, señala Antonio Caballero.

"Y llegan colombianos y obligados a tocar una cumbia colombiana, hasta bachata para los portorriqueños y dominicanos [...] Uno hace un poco de sociólogo cuando se sienta en un escenario [...] Si toco un vals criollo típico limeño y no hay reacción entonces le toco un vals del norte, porque hay mucha gente que viene de Trujillo y de Chimbote, que es la zona norte del Perú casi en la frontera con Ecuador, entonces el trino de la guitarra es distinto, es como más lastimero y ahí te das cuenta que provoca otra cosa. O tocas una cumbia conocida o tocas un bolero... ves la gente que está viniendo, que está llegando" (Antonio Caballero).

\subsubsection{Nuevas trayectorias y redes musicales}

Los músicos que inauguraron el viaje de las prácticas musicales criollas y afroperuanas a nuestro país en el período de la postdictadura fueron los integrantes de Fiesta Negra, primera agrupación de bailarines y músicos afroperuanos que emigró a Santiago. Formada en los años 80 en Lima por los bailarines Jesús Moreno (su director) y María Landó, la integraban además los músicos percusionistas Antonio Caballero, José Antonio Medina, Alejandro Reyes y Martín Zegarra. En su primer viaje a Chile, en el verano de 1989, son contratados por el Casino de Arica, y se presentan también en Iquique, donde son contratados para realizar una actuación

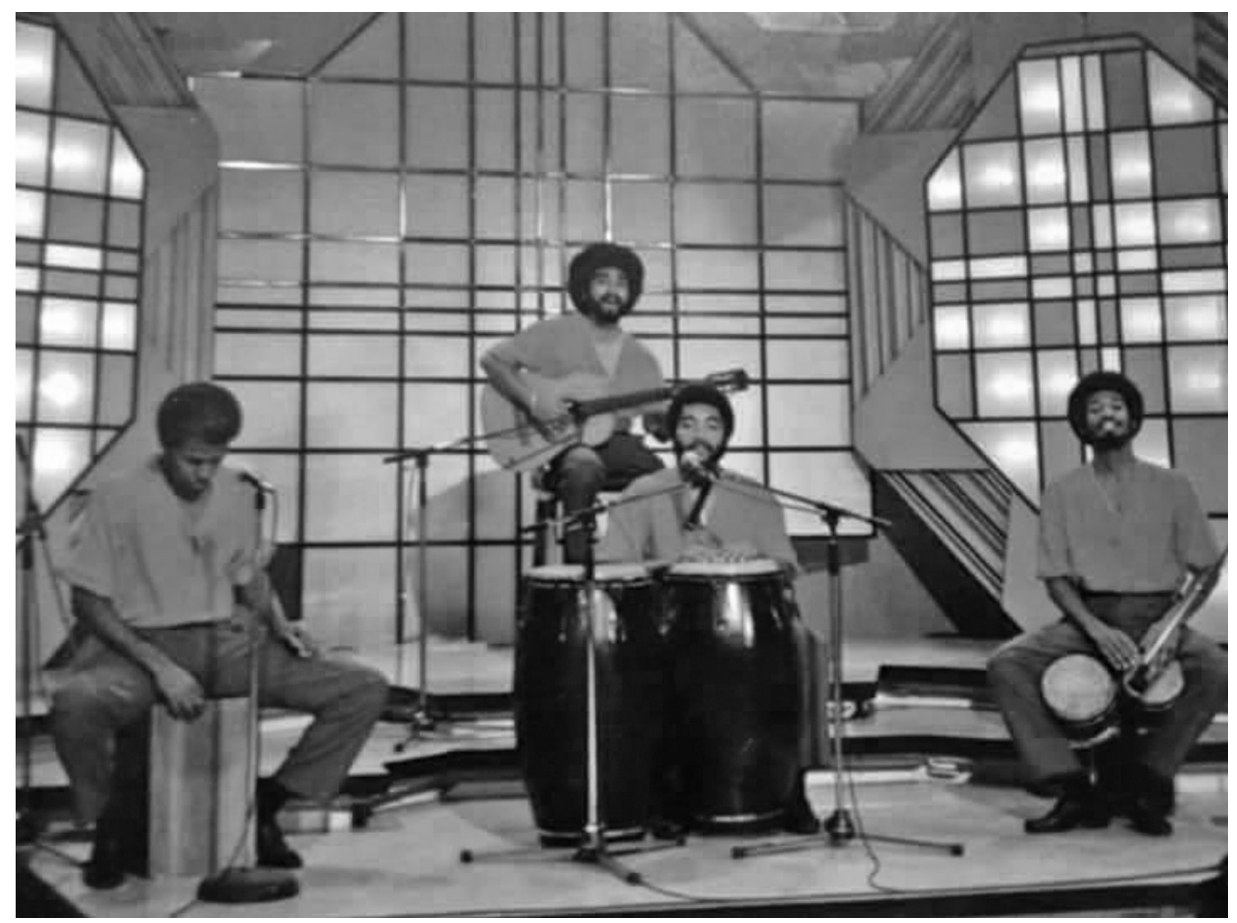

Foto 3. Músicos del Grupo Fiesta Negra en un set de televisión, ca. 1989. 
en Santiago en el programa de televisión "Sábados Gigantes”, conducido por "Don Francisco" (Mario Kreutzberger) para conmemorar las fiestas patrias peruanas (28 de julio, 1989).

"Ahí comenzó todo este rodaje interminable de actuaciones hasta el año 91, 92 y el 93 en que nos separamos. [...] solo hacíamos música afroperuana. En ese momento la música era un show impactante y la pareja tenía una forma de bailar, de pasos y saltos, muy espectacular. Y nos fue muy bien. Actuamos mucho tiempo en la Taberna Capri [calle San Antonio], en el Maxim [en Avenida Matta], en El Rodeo, locales emblemáticos en su tiempo" (Antonio Caballero).

Tras la separación, los músicos de Fiesta Negra permanecen en Santiago. Forman el grupo Canela (1993-1996) al que integran la bailarina afroperuana Katty Vásquez. Actúan en diversos locales del circuito así como en programas de televisión de gran audiencia: "Sábados Gigantes"; programa "Acompáñame" conducido por Julio Videla; "Cordialmente" conducido por Patricia Maldonado con Hernán Pereira; Programa "Éxito" conducido por José Alfredo "Pollo" Fuentes.

En paralelo, Antonio Caballero (ahora como guitarrista) y José Antonio Medina junto con el cantante y guitarrista Luis Chávez forman un nuevo trío de música criolla, La Nueva Voz (1993-1997), con un repertorio de valses peruanos y boleros, principalmente. En 1994, el guitarrista Oscar Álvarez, recién llegado a Santiago, ingresa como primera guitarra en reemplazo de Luis Chávez. Hacen una temporada larga, de cuatro años, como grupo estable en El Refrán (calle Larraín, comuna de La Reina), local nocturno dedicado a rutinas de humor en las que participan, entre otros, Ricardo Meruane, Natalia Cuevas, Oscar Gangas y el Profesor Rossa (Iván Arenas).

Otro núcleo de músicos limeños viajará en plan de gira profesional entre diciembre de 1989 y febrero de 1990 al norte de Chile. De ellos permanecerán en el país los guitarristas Germán Cruz y Tino Alegría, quienes de Arica viajan a Iquique, lugar donde coinciden con el recién llegado José Luis La Cruz y forman una alianza musical que se mantiene a la fecha. En mayo de 1990 llegan a Santiago donde se presentan como Tres Sabores del Perú (1990 a la fecha), trío de música criolla y afroperuana. La primera formación es: Germán Cruz ( $1^{a}$ guitarra y canto), Tino Alegría (primera voz y $2^{a}$ guitarra), José Luis La Cruz (percusión, canto y, luego, zapateo y baile). Se suma en 1992 Daniel Lavalle (canto y percusión), y con esta modalidad de cuarteto funciona hasta 1995, cuando se integra Raúl de la Cruz. Ha participado esporádicamente en sus actuaciones, desde 1992, la bailarina afroperuana Rosa Vargas, reforzando la presencia de la música negra peruana en la performance del grupo, iniciada previamente con el duelo de zapateo de José Luis La Cruz y Daniel Lavalle.

A la fecha, Tres Sabores del Perú se mantiene activo, pero con cambios de integrantes. Desde 2012 actúan de manera estable en locales del centro de la ciudad pertenecientes a la cadena de restaurantes peruanos El Ají Seco. Los actuales integrantes son Germán Cruz, Antonio Caballero, José Luis La Cruz y Raúl de la Cruz. 


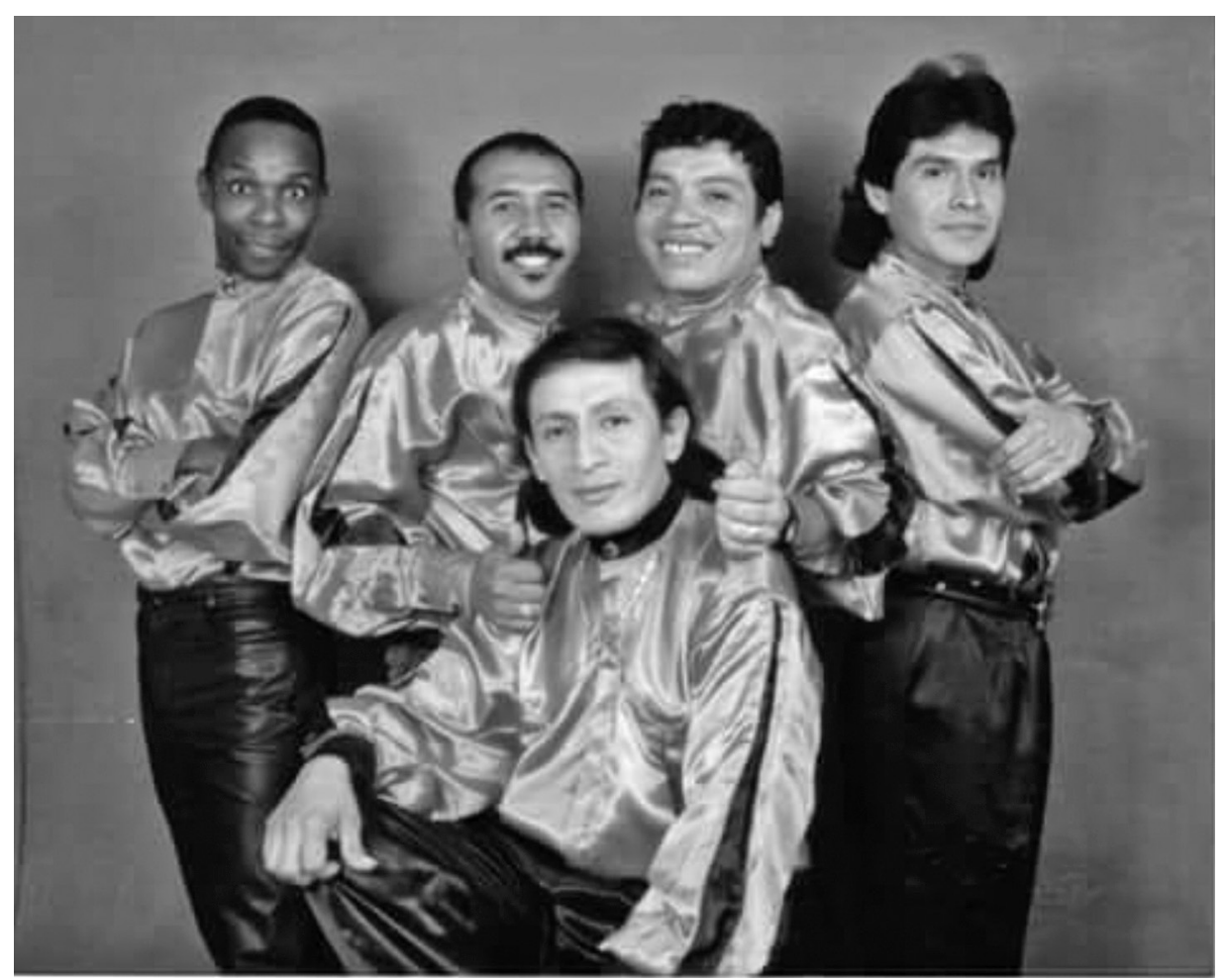

Foto 4. Grupo Tres Sabores del Perú, 2014.

\subsubsection{Sentimiento Negro en Chile: nuevos puntos de encuentro}

La "música negra”, como la llaman los propios músicos peruanos y que en este texto hemos mencionado como música afroperuana, constituyó una novedad para los chilenos en los años 90. Existen escasos antecedentes, como el de la visita a Santiago de la Agrupación Perú Negro en $1972^{38}$.

La incorporación del zapateo al espectáculo estará presente en las tempranas actuaciones en el Paseo Ahumada en 1990 del trío Tres Sabores del Perú, y luego también en las actuaciones del trío La Nueva Voz. Este número, el desafío o duelo de zapateo, constituyó siempre un momento de gran interés para el público chileno y fue el primer germen de un giro hacia la música negra en las presentaciones de estos músicos, que se consolidará en 1998 con la creación de la agrupación Sentimiento Negro del Perú. Formada por los integrantes del trío La Nueva Voz, al que se sumaron los músicos Daniel Lavalle y Sergio Arroyo y la pareja de bailarines Rosa Vargas y Aldo Pheifer, esta agrupación -reconocida por Daniel Lavalle como "el grupo más fuerte y representativo de Perú que tenemos

38 Para una mayor información sobre aspectos históricos y contemporáneos de la negritud musical en Chile, ver González y Rolle (2005), Ramos (1999) y Rondón (2014). 
aquí en Chile"- representa la culminación de este giro a lo afroperuano en la escena musical peruana en Santiago.

"Antes no se escuchaba música negra [peruana] en Chile [...] No había el nombre de alguien que la gente conociera o que existía música negra. No. Eso era totalmente desconocido. Entonces, introducir música negra era complicado. No sabíamos cómo iba a reaccionar la gente. Pero poco a poco se fue dando ese condimento interesante y fue mucho más rápido entre los jóvenes” (Oscar Álvarez).

"En nuestro show, aparte de la música peruana, hacíamos algunos boleros y poco a poco se comenzó a introducir lo que es el zapateo negro, que a la gente le llamaba muchísimo la atención. Era lo que más esperaban. Como Antonio [Caballero] y José Antonio [Medina] zapateaban aprovechamos para presentar este espectáculo y tuvo mucha recepción en la gente. Era algo que no esperábamos. La gente probablemente no lo había visto nunca. No existía ese nexo Perú-Música negra. No les encajaba. Los sacaba de cuadro y les encantaba. Y ese fue el condimento para introducir algo de la música negra también" (Oscar Álvarez).

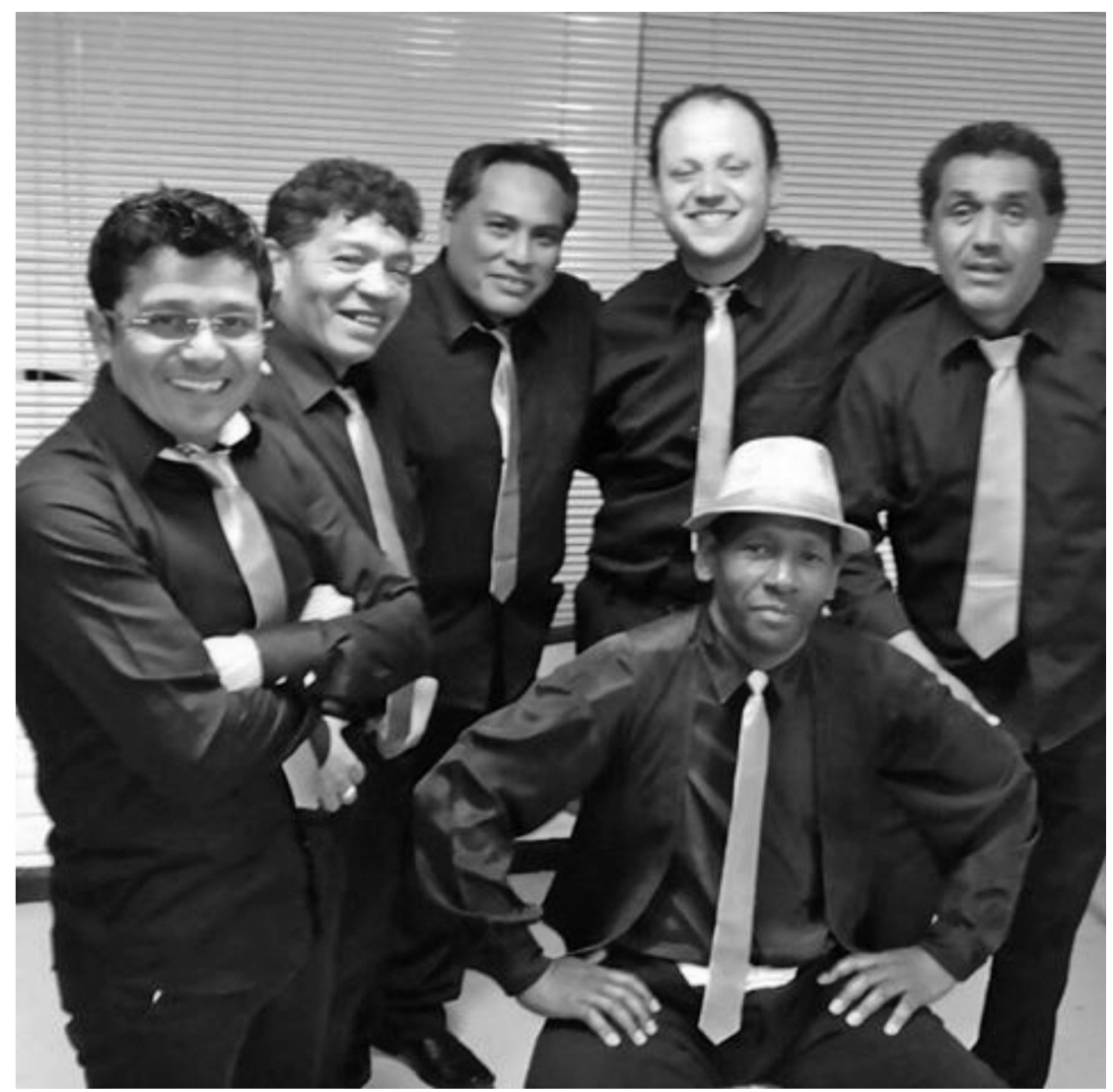

Foto 5. Músicos de la agrupación Sentimiento Negro del Perú. 


\subsubsection{Bailar y musicar con quimba ${ }^{39}$}

En el ejercicio de la performance estos músicos revelan en sus acto aspectos interesantes de su relación con los sistemas musicales de los que hacen parte, así como sus modos individuales de resolver los gajes del oficio, cuestión especialmente decisiva en los momentos donde se conecta creativamente su individualidad con los estándares y modos de hacer una buena performance. La vital relación entre el "musicar" y el bailar es un aspecto muy importante en la cultura afroperuana. La poderosa interacción entre música y baile reenvía directamente al corazón de la convivencia festiva, dispositivo central en la continuidad y transmisión de la cultura afrodescendiente en toda América. Es en la fiesta donde músicos y bailarines movilizan e impregnan con su ritmo el flujo de la convivencia, asociada al fortalecimiento de la comunidad.

Este vínculo no solo opera en el nivel de la convivencia colectiva. Es también un elemento presente en los procesos creativos de estos sistemas. Más aún, existen casos en los que la copresencia del bailar y musicar es una condición para la "inspiración", una fuente para nutrir en tiempo real el flujo de la inventiva musical y coreográfica. Para ilustrar esta conexión creativa entre el musicar y bailar, nos remitimos a los testimonios de Rosa Vargas, bailarina, y de Oscar Álvarez, guitarrista, quienes se conocen desde antes de su partida a Santiago (en 1992 y 1994, respectivamente).

La retroalimentación entre bailar y musicar es ilustrada por Rosa Vargas en la conexión que ella logra al bailar acompañada por Oscar Álvarez y su guitarra:

"Oscar sabe la música que a mí me mueve y el de repente me hace esos toques porque ya sabe lo que me motiva a mí en mi corazón. Él me conoce ya, de tantos años [...] A él le inspira lo que yo hago y a mí me inspira los toques que puede hacer" (Rosa Vargas). "Para mí tiene que haber una conexión con el que toca. Yo cuando bailo, miro al percusionista y quiero que él me mire también, porque es un diálogo constante. Y eso es lo que uno transmite al público ¿me entiendes? Que haya una complicidad, que haya un diálogo entre ambos, entre la percusión y yo y mi cuerpo" (Rosa Vargas).

Y profundiza su descripción de esta conexión cuando ocurre la situación de improvisación:

"Y eso se nota cuando tú tienes que bailar sola, por ejemplo. Hacer un solo, que los músicos toquen y tú tienes que inspirarte y hacer un solo, algo improvisado. ¿Cómo te inspiras? Cuando tú bailas algo improvisado tú no tienes nada marcado, uno no sabe lo que va a hacer. Va a depender de quién te esté tocando, porque el que te está tocando te empieza a hacer un llamado, que para mí, es un llamado a mi alma, a mis sentimientos - no a mi mente- y yo transmito lo que siento en ese momento. Mis ojos pueden estar abiertos pero es como si yo estuviera con los ojos cerrados y empiezo a

39 Concepto usado por músicos peruanos entrevistados para connotar una cualidad asociada a la buena performance musical: con ritmo y con sabor. En Perú se le utiliza habitualmente para connotar, por ejemplo, las fintas o "cachañas” de los jugadores negros del Club Alianza Lima o el baile y el andar garboso de los negros. 
sentir la música y me dejo llevar por lo que estoy sintiendo. Y es esa la conexión que falta con el músico y que es la conexión que yo tengo con el Oscar, por ejemplo, y que la tenía también con el José Antonio [Medina]. José Antonio es la única persona que como que me leía el pensamiento, igual que el Oscar" (Rosa Vargas).

"Eso me hace falta. Extraño mucho juntarme con ellos, hacer música y cantar y bailar. Lo extraño. Eso me encanta, me retroalimenta. Yo me he juntado con músicos de acá, hay muchos chicos chilenos que tocan y se juntan y tocan pero ellos tocan lo que aprendieron y yo los escucho pero no siento un llamado de ellos como para que cuando los escuche tocar, yo me pare y empiece a bailar [...] Para que pase eso los músicos tienen que entender que tocar no es solo tocar y perfeccionarse y hacer bien los toques. Es tocar con el alma. Sentir. Sentir lo que estás haciendo ¿me entiendes?” (Rosa Vargas).

Por su parte, Oscar Álvarez es un músico que aunque no baila establece en el baile, el de otros, un fundamento de su oficio de hacer música, que fue decantando empíricamente. Lo explica así, en referencia a su experiencia de acompañar el baile de la marinera en peñas criollas de Lima:

"En Lima te puedes dar cuenta que el movimiento del bailarín es un poco más garboso, hay movimientos que no se condicen con la métrica exacta, si uno quisiera ponerlo en la cuadratura. Entonces, a eso se deben estos ritardandos y estas fórmulas de cómo se aborda la guitarrística y que no los encuentras en otro lugar. O es que el bailarín se empata con las formas o las atmósferas que le das o es que tú te empatas con las atmósferas que te da él. Yo no encuentro otra forma de cómo conectarlo. Porque el cajón hace una base, no te dicta. No es un solfeo rítmico que te pueda decir aquí es donde están los puntos fuertes, son contratiempos pero igual, esta es la forma. En cambio en el baile sí. Sí, lo encuentras. Sea un movimiento de la mano, del cuerpo. Entonces, yo viendo bailar me he imaginado con los movimientos corporales el solfeo rítmico y ahí desarrollo la parte melódica. Y resulta. Resulta porque, claro, si al final lo que tú estás viendo es un movimiento de acuerdo a la atmósfera que le pones al bailarín” (Oscar Álvarez).

"No hay otro ingrediente tan importante como es el baile para que te dé ciertos movimientos, que uno no idearía así nomás si no se está también alimentando visualmente. Eso es para mí. O a lo mejor será porque yo también acompaño a muchos grupos de danza y entonces también eso me ha llamado a verlo más, pero yo creo que sí es importante, muy importante" (Oscar Álvarez).

La profundidad del arraigo de estos particulares movimientos del baile popular en ciertos barrios limeños es una clave para apreciar el mundo de donde arranca y se proyecta la creatividad en los oficios de estos artistas criollos y afroperuanos, ahora radicados en Santiago:

"Uno se puede dar cuenta si uno ha estado en los callejones en Lima donde se hace música popular de verdad, ahí metido donde están los cultores, y la gente que baila es la gente de la casa, la gente del barrio y que toda su vida ha escuchado esas músicas. No solo la gente que baila en el escenario sino la gente que baila en el día a día, que está curtida en eso, y se alimenta y pone su radio al mediodía a escuchar siempre lo mismo. Esas personas, para mi parecer, me alimentan más que un bailarín de escenario. [...] ¿Por qué? Porque para mí es como la fuente. Cuando he ido a una encerrona 
por ahí y observaba a unos viejitos bailando, era algo tremendo ¿De dónde les sale esa cosa, ese salero, esa forma? 'Bailar en una loza', te dicen. En un círculo. Bailar en ese pedacito. Y es verdad pues. No sé cómo se las ingenian con el cuerpo, la cosa es que lo hacen así. Entonces, ¿cuántas posibilidades tiene el cuerpo de expresar todo? Y si te das cuenta, por lo menos para mi percepción, veo que esa es la quimba, la forma como aborda el peruano el vals, el vals de callejón. Es totalmente distinto. Es un movimiento muy cimbreante que tiene mucho que ver con la fórmula como se toca, como se interpreta ese tipo de vals, que está totalmente en una rítmica toda contrapuesta, donde uno está tocando en $3 \times 4$, está tocando en $6 \times 8$, está tocando en cuartinas, todo al mismo tiempo. Y el único momento en que yo me encuentro en este ambiente, en esta fórmula, es cuando veo el baile [...] Pero ¿y cómo hacen esto? Está ahí. Ahí está puesto el tema [...]. Para mí es como un dictado eso, me va dictando y de ahí lo transpongo como un solfeo y después le pongo la melodía. Es como una fuente"(Oscar Alvarez).

Nos hemos detenido en una observación casi microscópica que informa, desde experiencias personales, respecto de matices y sutilezas de los modos de realizar creativamente la música criolla y afroperuana, tanto en el musicar como en el bailar. Esta particular manera de encontrar en el baile -con quimba- una fuente inspiradora de nueva música y de radicar en los músicos el "llamado" para salir a bailar, señala una dimensión más interna y de acceso más restringido desde donde también se pueden calibrar los mutuos acercamientos, aprendizajes, compenetraciones y eventuales nuevos mestizajes, en curso o por venir, implicados en esta experiencia del encuentro intermusical propiciado por las migraciones latinoamericanas en Chile.

\subsubsection{Diálogos musicales interculturales: la cueca y la marinera}

Dos géneros emblemáticos de sus respectivos países, emparentados desde el origen y empapados en varias culturas regionales y locales, se (re)encuentran desde una nueva situación que podríamos calificar como postnacional en cuanto están menos presentes los notables mecanismos nacionalistas que buscan cautelar la autenticidad de cada género. Se trata de la cueca chilena y la marinera peruana, cuyas prácticas han generado un notable diálogo intermusical, propiciado tanto en el espacio de los músicos peruanos en Santiago como en aquel construido en los últimos quince años por la nueva promoción de jóvenes cuequeros urbanos, protagonistas de una nueva escena del cultivo de este género en el país. Un testimonio acerca de los puntos de afinidad específicos entre ambos géneros lo da Antonio Caballero:

"La cueca chora o la cueca del puerto nos gusta mucho, nos encantó, es lo más parecido a la marinera limeña y es con la que más comulgamos nosotros, más que con la cueca campesina. En las introducciones, por ejemplo, las improvisaciones son distintas, tienen mucho bordoneo, tienen más quimba como decimos en el Perú, más sabor, más variedad musical que los dos o tres acordes que tienen las introducciones normales. Da la posibilidad de hacer otro tipo de arreglos de voces. Te da otro campo" (Antonio Caballero).

Explorar esa potencial zona de contacto entre cueca y marinera fue lo que decidió el destino del viaje del guitarrista Oscar Álvarez en 1994: 
"Y ahí resultó que decidí viajar o a Brasil o a Chile. Y como se me metió siempre ese gusanito de la curiosidad por conocer la cueca; porque en la Casa de Abelardo lo más importante era la marinera limeña y por eso mismo opté en ese minuto de venir aquí a conocer la música chilena y sobre todo la cueca" (Oscar Álvarez).

Veintiún años después, Álvarez aprecia un cambio, una apertura del músico actual chileno a estas prácticas y repertorios:

"[el músico chileno] se está introduciendo mucho más en la rítmica, que antes no era tan importante" (Oscar Álvarez).

Y describe su percepción de algunos aspectos de este diálogo intermusical:

"En la forma de abordar los géneros hoy día. De hecho tú ves que la música tradicional, de lo poco que se practica de lo que se conoce como música tradicional, ya no está hecha a la usanza antigua. Ya no respetan tan puramente el cómo era la música chilena. La cueca, por ejemplo, es una cosa que hoy día, sea como la llamen, se abrió a todos los campos, se le introdujo cosas de otros géneros y en lo que llaman la cueca urbana -que es una invención para mi entender- es el condimento que le faltaba, en la rítmica sobre todo y que no lo tenía tan presente. Eso para mí marca un desarrollo rítmico, porque si tú escuchas músicos de hace 20 años en Chile (...) los músicos no estaban muy predispuestos a la rítmica, no usaban mucha rítmica. Costaba mucho introducirlo. Tocar con un músico chileno era complicado porque no te podía entender el lenguaje de un vals de esa forma. Este tenía un lenguaje distinto. Y para qué hablar de la música negra... Eso era una cuestión terrible, por la rítmica; porque no había esa costumbre tampoco de introducirse a las rítmicas porque [en Chile] los ritmos son más estáticos, los géneros son más tranquilos. Entonces no hay rítmica aditiva, polirrítmica. Eso acá, en la música chilena, era casi impensable, por ende no existía esa cultura del músico de decir 'Yo necesito utilizar ritmos contrapuestos'. No existía eso 20 años atrás [...] Si tocabas con un músico popular era tremendo plantearle algo así. [...] Podías tocar con músicos extranjeros, centroamericanos, y ellos sí entendían este lenguaje y se amoldaban; pero el músico chileno no, porque no tenía los referentes tampoco" (Oscar Álvarez).

Para el cierre de este punto, solo constatar un hecho elocuente y decisivo en el acercamiento de los mundos musicales peruanos y chilenos: la presencia y uso transversal del cajón peruano en la práctica de la cueca urbana así como en otras escenas musicales locales. Este fenómeno tiene dimensiones múltiples: talleres y clínicas de aprendizaje con maestros peruanos y chilenos, colectivos dedicados regularmente a la práctica de este instrumento, importación de instrumentos desde Lima y desarrollo en plaza de una oferta múltiple de parte de lutieres peruanos y chilenos. El cajón peruano ya forma parte de la vida musical del país, experiencia que constituye un nuevo capítulo de los viajes transnacionales de este extraordinario instrumento, sonoridad-eje de la cultura musical afroperuana. En las sonoridades del cajón, repartidas ampliamente en la ciudad de Santiago, podemos hoy escuchar y seguir la huella musical de la diáspora peruana en nuestro país. 


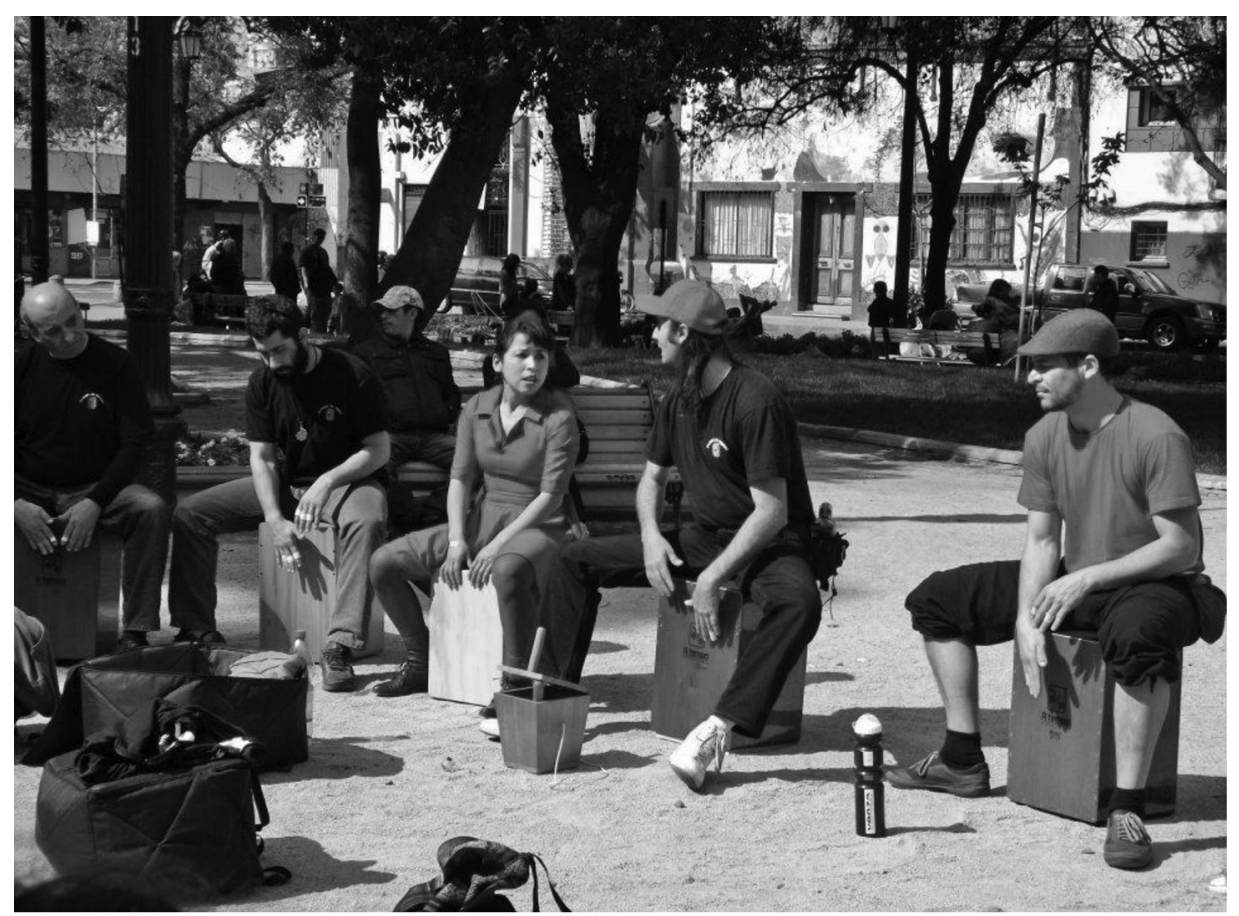

Foto 6. Miembros de la agrupación chilena "Cajones de Yungay" ensayando en la Plaza Yungay, bajo la dirección de Caruso Moraga.

\section{CONCLUSIONES}

Una mirada más general al fenómeno del mestizaje a partir de la producción musical de los inmigrantes, nos lleva a comprender la experiencia migratoria como un fenómeno complejo que se inició mucho antes de la llegada y asentamiento de estas poblaciones en nuestro país. Es así que en varias de las trayectorias de músicos es posible distinguir la importancia de la migración de poblaciones al interior del Perú, que en nuestro caso están ilustradas por desplazamientos de la Sierra a Lima o de Chincha a Lima. Se trata de migraciones del campo a la ciudad vividas por las familias de origen de nuestros entrevistados, que les permitió mantener un vínculo estrecho con esas culturas locales aun cuando todos hicieron gran parte de sus vidas en la capital.

Los procesos de mestizaje que aquí han tenido lugar deben ser entendidos como procesos de larga duración, relevando la mezcla entre elementos que no eran puros al momento de llegar al nuevo territorio, sino que ya habían sido transformados por desplazamientos anteriores, oscilando entre el campo y la ciudad, la tradición y la modernidad, el mundo indígena y el occidental.

Volviendo a nuestro caso, podríamos señalar que los mestizajes culturales entre chilenos y peruanos mediante la música, no representan el encuentro de dos identidades comprendidas como bloques totales y homogéneos que podrían 
asimilarse a la idea de nación. La trayectoria de los músicos migrantes va revelando la influencia de desplazamientos anteriores y sus respectivas culturas musicales (serranas, afroperuanas, etc.). Se trata más bien de encuentros fragmentarios, que a la manera de un caleidoscopio pueden desplegarse y rearticularse en otros territorios a partir de numerosas posibilidades. A este propósito nos preguntamos a modo de una apertura: ¿Cómo se despliegan las posibilidades de esta diversidad cultural y musical peruana en Santiago? ¿con qué mundos musicales se concretan sus intercambios?, ¿cuáles son sus especificidades y sus posibilidades de mutua influencia respecto de las prácticas culturales locales?

Estas preguntas nos remiten a un segundo punto relacionado con la constitución de una escena musical peruana en la ciudad de Santiago: ¿Cómo se explica su arraigo y su relativo éxito en la sociedad chilena? Según vimos, la época de llegada de los inmigrantes peruanos coincide con un período de reapertura y de resignificación de la historia política en Chile, luego de la recuperación de la democracia. El testimonio de los músicos inmigrantes nos permite dimensionar, desde otra experiencia cultural, las transformaciones en el modo de vivir y compartir la música entre chilenos, particularmente en relación con la fiesta y el baile, la sociabilidad festiva.

Como hemos revisado, durante las últimas décadas la imagen del Perú se ha enriquecido lentamente en el imaginario de los chilenos. Hoy, resultado de la representación que el propio país peruano exporta de sí mismo, se trata de un país valorizado en el mundo por su gastronomía y por la mezcla de sus tradiciones culturales (andina, afro, criolla, española, japonesa, etc.).

La dinámica migratoria intrarregional en América Latina de los últimos veinticinco años se ha comenzado a apreciar y reconocer como un activísimo polo de crecimiento de la diversidad y densidad de elementos que hacen parte de un cada vez más fluido diálogo intercultural. En este escenario la música adquiere el rango de un revelador muy expresivo, incluso decisivo, de los paisajes e imaginarios culturales asociados a la migración latinoamericana en Santiago de Chile.

Es probable que esta experiencia, como la del caso de la escena de las músicas peruanas en Chile explorada en este trabajo, constituya un elemento motivador importante del renovado interés que se aprecia en muchos músicos chilenos jóvenes por aprender e incorporar estas músicas latinoamericanas a sus propias prácticas y proyectos musicales.

La actual presencia de tradiciones musicales latinoamericanas, especialmente de aquellas afroamericanas, antes poco familiares para los músicos y públicos locales; la apertura de los músicos jóvenes a conocer empíricamente las sutilezas rítmicas y sonoras de la música criolla y la música negra del Perú, por ejemplo, es una expresión del nuevo giro latinoamericano que ha comenzado a impregnar la vida musical en la ciudad capital de Chile.

A diferencia del movimiento de latinoamericanización musical de los años 1960, este interés se traduce en la toma de contacto y alianza con músicos latinoamericanos, en viajes por la región y en la participación en talleres locales de música y danza de carácter transnacional, todas acciones que evidencian un creciente interés por conocer in situ los elementos, códigos, técnicas y prácticas implicadas 
en diversos sistemas musicales de nuestra región. De este modo, la imagen actual de Santiago se puede representar como un activo crisol multicultural de sonoridades y musicalidades múltiples, imagen que contrasta con la del Santiago "gris, frío, apagado y sin lugar para la música" 40 que acogió a los primeros músicos peruanos que llegaron a este lugar en la década de 1990.

\section{BIBLIOGRAFÍA}

Abusada Salah, Roberto y Cinthya Pastor Vargas

2008 Migración en el Perú. Lima: Instituto Peruano de Economía (IPE).

Acevedo Elgueta, Claudio et al.

1999 Víctor Jara. Obra musical completa. Santiago: Fundación Víctor Jara.

Albornoz Morales, Pablo

2015 La música en la disposición existencial de inmigrantes-emigrantes peruanos, ecuatorianos y colombianos. Un abordaje desde las prácticas de escucha y de ejecución musical. Seminario de grado, Licenciatura en Sociología, Departamento de Sociología, Facultad de Ciencias Sociales, Universidad de Chile. Profesora guía: Marisol Facuse.

Aparicio, Frances R. y Cándida F. JáQuez

2003 "Introduction”, en Frances Aparicio y Cándida Jáquez (editores). Musical Migrations: Transnationalism and Cultural Hybridity in Latin/o America. Nueva York: Palgrave Macmillan, pp. 1-10.

BECKER, HOWARD S.

2009 Outsiders: Hacia una sociología de la desviación. Buenos Aires: Siglo XXI.

2008 Los mundos del arte. Buenos Aires: Universidad Nacional de Quilmes.

BennetT, ANdy

2004 “Consolidating the Music Scenes Perspective”, Poetics, XXXII/3-4 (junio-agosto), pp. 223-234.

Bennett, Andy y Richard A. Peterson

2004 Music Scenes. Local, Translocal, and Virtual. Nashville: Vanderbilt University Press.

Bertaux, Daniel

1997 Le récit de vie. París: Armand Colin.

Bourdieu, Pierre

1998 [1979] La distinción. Criterios y bases sociales del gusto. Madrid: Taurus

Bruner, Jerome Seymour

2013 La fábrica de historias: derecho, literatura, vida. Madrid: Fondo de Cultura Económica.

Cámara de Landa, EnRiQue

2008 “¿Diáspora o migración? Instrumentos, músicas y músicos fuera de casa”, en Rubén Gómez Muns y Rubén López Cano (editores). Música, ciudades, redes: creación musical e interacción social. Actas del X Congreso de la SIBE, Sociedad de Etnomusicología; VCongreso IASPM-España; II Congreso de músicas populares del mundo hispano y lusófono.

40 Ver cita de Oscar Álvarez en página 28 del trabajo. 
Editado por Rubén Gómez Muns y Rubén López Cano. Salamanca: SIBE-Obra Social Caja Duero.

Charles-DominiQue, Lug y Laurent Aubert

2009 "Introduction”, Cahiers d'éthnomusicologie. Mémoire, traces, histoire, № 22, pp. 11-14.

Departamento de Extranjería y Migración del Ministerio del Interior y Seguridad Pública, Gobierno de Chile

2016 Migración en Chile 2005-2014. Santiago: Ministerio del Interior y Seguridad Pública. En: www.extranjeria.gob.cl/ (revisada el 19 de mayo de 2016).

DeNora, Tia

2004 Music in Everyday Life. Cambridge: Cambridge University Press.

Facuse M., Marisol

2012 "Le monde de la poésie populaire chilienne: sociabilités et imaginaires dans le paysage culturel actuel”, Mémoires et imaginaires dans les sociétés d'Amérique Latine. Harmonie, contrepoints, dissonances. Dirigido por François Laplantine. Rennes: Presses Universitaires de Rennes, pp. 55-64.

2011 "Poesía popular chilena: imaginarios y mestizajes culturales", Atenea, 504 (segundo semestre), pp. 41-53.

Feldman, Heidi Carolyn

2009 [2006] Ritmos negros del Perú. Reconstruyendo la herencia musical africana. Lima: Instituto de Etnomusicología-Universidad Católica del Perú.

Fernández M., Mireya

2008 "Diáspora: la complejidad de un término", Revista Venezolana de Análisis de Coyuntura, XIV/2 (julio-diciembre), pp. 305-326.

Forné Verdugo, Daniela

2015 Prácticas de reconocimiento e igualdad. Inmigración peruana en Recoleta. Taller de investigación Sociológica II, Licenciatura en Sociología, Departamento de Sociología, Facultad de Ciencias Sociales, Universidad de Chile. Profesora guía: Marisol Facuse.

Gilroy, Paul

1993 The Black Atlantic. Modernity and Double Consciousness. Londres, Nueva York: Verso.

González Rodríguez, Juan Pablo y Claudio Rolle

2005 Historia social de la música popular en Chile, 1890-1950. Santiago: Ediciones Universidad Católica de Chile y Casa de las Américas.

Heinich, Nathalie

1991 La Gloire de Van Gogh. Essai d'anthropologie de l'admiration. Paris: Les Éditions de Minuit.

Hennion, Antoine

2002 La pasión musical. Barcelona: Paidós Ibérica.

Hobsbawm, Eric

2002 [1983] "Introducción: la invención de la tradición", en Eric Hobsbawm \& Terence Ranger (editores). La invención de la tradición. Barcelona: Crítica, pp. 7-21. 
Imilan, Walter, Carolina Stefoni y Francisca Márquez (editores)

2015 Rutas migrantes en Chile. Habitar, festejar y trabajar. Santiago de Chile: Ediciones Universidad Alberto Hurtado.

La Cruz Bonilla, Juan

2010 "Más allá de la cholificación: movilidad ascendente entre los aimaras de Unicachi en Lima”, Debates en Sociología, No 35, pp. 132-137.

Laplantine, François

2008 Le méttissage. París: Téraèdre.

Laplantine, François y Alexis Nouss

2007 Mestizajes: De Arcimboldo a Zombi. México: Fondo de Cultura Económica.

LEón F., JAVIER

2010 "Música tradicional y popular en la costa peruana", en Albert Recasens y Christian Spencer (editores). A tres bandas. Mestizaje, sincretismo e hibridación. Madrid: Sociedad Estatal para la Acción Cultural Exterior \& Ediciones Akal, pp. 197-204.

Merino Montero, Luis, Rodrigo Torres, Cristián Guerra y Guillermo Marchant

2013 Prácticas sociales de la música en Chile, 1810-1855. El advenimiento de la modernidad en la cultura del país. Santiago: RIL editores.

Ministerio de Desarrollo Social, Gobierno de Chile

2015 Casen 2013. Inmigrantes. Síntesis de resultados. Santiago de Chile: Ministerio de Desarrollo Social, Gobierno de Chile. En: http:/ /observatorio.ministeriodesarrollosocial.gob.cl/documentos/CASEN_2013_Inmigrantes_revisada.pdf (revisada el 19 de mayo de 2016).

Passeron, Jean-Claude

2011 El razonamiento sociológico. El espacio comparativo de las pruebas históricas. Traducción de José Luis Moreno Pestaña. Madrid: Siglo XXI de España Editores, S.A.

Pelinski, RAMón

2000 "Diásporas del tango rioplatense", Invitación a la etnomusicología. Quince fragmentos y un tango. Madrid: Akal ediciones, pp. 176-200.

PÉQuignot, BRUNo

2007 La question des oeuvres en sociologie des arts et de la culture. París: L’Harmattan.

Póo Figueroa, Ximena

2012 Inmigrantes peruanos en las "fronteras" de la Plaza de Armas de Santiago de Chile. Itinerarios de sentidos y comunicación transnacional/transcultural en la ciudad. Tesis doctoral en Estudios Latinoamericanos, Facultad de Filosofía y Humanidades, Universidad de Chile. Profesora guía: Alicia Salomone.

RAMOS VENEREO, Zobeida

1999 "Cubanos en Bellavista", en Rodrigo Torres (editor). Música popular en América Latina. Actas del $2^{\circ}$ Congreso de la IASPM-AL. Santiago: Fondo Nacional para el Desarrollo Cultural y las Artes (Fondart), pp. 157-164.

Rey, Mario

2004 "La música afroperuana en Miami y la construcción de memoria e identidad", en Actas V Congreso IASPM-AL, Rio de Janeiro, Brasil. En: http:/ / www.iaspmal.net/ wp-content/uploads/2011/12/MarioRey.pdf 
Rodríguez Morales, Eugenio

2008 El himno que se baila. Valparaíso: Fondo de Cultura del Gobierno Regional de Valparaíso.

Rondón Sepúlveda, Víctor

2014 "Música y negritud en Chile. De la ausencia presente a la presencia ausente", Latin American Music Review, XXXV/1 (primavera-verano), pp. 50-87.

SÁNCHEZ FuARros, Í̃̃IGO

2008a "Cubanos en diáspora. Nuevos escenarios para la investigación (etno)musicológica”, en Josep Martí (editor). Fiesta y Ciudad: Pluriculturalidad e Integración. Madrid: CSIC, pp. 169-188.

2008b “Esto parece Cuba!” Prácticas musicales y cubania en la diáspora cubana. Tesis doctoral en Antropología Social y Cultural, Universidad de Barcelona. Profesores guías: Josep Martí i Pérez y Gemma Orobitg Canal.

Stokes, Martin

1994 "Introduction", en Martin Stokes (editor). Ethnicity Identity and Music: The Musical Construction of Place. Oxford/Providence, USA: BERG Ethnic Identities Series, pp. 1-24.

Tijoux-Merino, María Emilia

2007 "Peruanas inmigrantes en Santiago. Un artecotidiano de la lucha por la vida", Polis. Revista Latinoamericana [En línea], 18. Publicado el 23 julio 2012, URL: http:/ / polis.revues.org/4185.

Tompkins, William D.

2011 Las tradiciones musicales de los negros de la costa del Perú. Lima: Centro de Música y Danza de la Pontificia Universidad Católica del Perú \& Centro Universitario de Folklore de la Universidad Nacional Mayor de San Marcos.

Torres Falcón, Marta

2012 Reseña "'La migración y sus efectos en la cultura', de Yerko Castro Neira (coordinador)", Sociológica, XXVII/77 (septiembre-diciembre), pp. 301-306.

Torres A., Rodrigo

2011 “Don José Zapiola, el 'Negro querido’ y las flautas de chinos. Mediaciones musicológicas de lo popular en el orden republicano chileno", en Coriún Aharonián (coordinador). Música/Musicología y Colonialismo. Montevideo: Centro Nacional de Documentación Musical Lauro Ayestarán, pp. 213-233.

2008 "Zamacueca a toda orquesta! Música popular, espectáculo público y orden republicano en Chile (1820-1860)", Revista Musical Chilena, LXII/209 (enero-junio), pp. 5-27.

2013 "Zamacueca a toda orquesta. Música popular, espectáculo público y orden republicano en Chile (1820-1860)" en Prácticas sociales de la música en Chile, 1810-1855. El advenimiento de la modernidad en la cultura del país. Santiago: RIL editores, pp. 93-118.

Toynbee, JASON y Byron Dueck

2011 "Migrating music", en Jason Toynbee y Byron Dueck (editores). Migrating Music. Londres/Nueva York: Routledge, pp. 1-17.

VÁsquez Rodríguez, Chalena

2010 Música y danza en la costa peruana [Colección La voz de los sin voz, volumen 5, Afrodescendientes]. Buenos Aires: Irco Video. 
s/f COSTA. Presencia africana en la cultura de la costa peruana. Relación de géneros, danzas e instrumentos musicales. Lima: CEMDUC, Centro de Música y Danza de la Pontificia Universidad Católica del Perú. En: http://cemduc.pucp.edu.pe/libros.html

\section{Entrevistas}

Entrevista a Tino Alegría (Mario Nunura Villanueva, Lima, 1962). Marisol Facuse y Rodrigo Torres. Santiago, 10 de septiembre de 2014.

Entrevista a Oscar Álvarez (Lima, 1970). Rodrigo Torres. Santiago, 5 de febrero de 2016.

Entrevista a Antonio Caballero (Lima, 1964). Rodrigo Torres. Santiago, 2 de marzo de 2016.

Entrevista a José Luis La Cruz (Lima, 1954). Malen Cayupi. Santiago, 2 de septiembre de 2014.

Entrevista a Daniel Lavalle (Lima, 1963). María Ignacia Villagra. Santiago, 5 de noviembre de 2014.

Entrevistas a Wendy Lozano (Lima, 1973). Marisol Facuse y Rodrigo Torres, Santiago, noviembre 2014; María Ignacia Villagra, Santiago, noviembre 2014.

Entrevistas a Rosa Vargas Advíncula (Lima, 1958). Malen Cayupi, Santiago, 13 de agosto de 2014; Rodrigo Torres. Santiago, 18 de febrero de 2016.

Entrevista a Martín Zegarra (Lima, 1960). Marisol Facuse y Rodrigo Torres. Santiago, 12 de octubre de 2014. 